\title{
1 Gene flow between two thick-billed grasswren subspecies with low dispersal creates a 2 genomic pattern of isolation-by-distance
}

3 Amy L. Slender ${ }^{1,4}$, Marina Louter ${ }^{1}$, Steven A. Myers ${ }^{2}$, Tessa Bradford ${ }^{1,2,3}$, Michael G.

4 Gardner $^{1,2}$ and Sonia Kleindorfer ${ }^{1}$

$5{ }^{1}$ College of Science and Engineering, Flinders University, GPO Box 2100, Adelaide, SA

6 5001, Australia

$7 \quad{ }^{2}$ Evolutionary Genomics, South Australian Museum, North Terrace, Adelaide, SA, 5000,

8 Australia

$9{ }^{3}$ The Australian Centre for Evolutionary Biology and Biodiversity and School of Biological

10 Sciences, The University of Adelaide, SA 5005, Australia

$11 \quad{ }^{4}$ Corresponding author. Phone: 0061882012805 Email: amy.slender@flinders.edu.au

12 Introgression between grasswren subspecies

13 Characterising gene flow facilitates conservation management. This study used genomic

14 markers to measure gene flow between thick-billed grasswren subspecies and found results

15 that support taxonomic identification of the two subspecies and suggests grasswrens have low

16 dispersal and may benefit from increased genetic diversity. Recognition of models of

17 divergence with gene flow will be necessary for future conservation management. 


\section{Abstract}

\section{Context}

20 In the era of the Anthropocene, habitat loss and environmental change threaten the

21 persistence of many species. Genotyping-By-Sequencing (GBS) is a useful molecular tool for

22 understanding how patterns of gene flow are associated with contemporary habitat

23 distributions that may be affected by environmental change. Two parapatric subspecies of the

24 threatened thick-billed grasswren (TBGW; Amytornis modestus) more frequently occur in

25 different plant communities. As such, a preference for plant community type could reduce

26 subspecific introgression and increase genetic diversity at the parapatric boundary.

27 Aims

28 We aimed to measure gene flow within and among two TBGW subspecies and tested

29 whether divergent genomic markers were associated with plant community type.

30 Methods

31 We sequenced 118 individuals from either of the two TBGW subspecies or in the region of

32 parapatry and identified 7583 SNPs through ddRADseq.

33 Key results

34 We found evidence of asymmetric gene flow and a genomic pattern of isolation-by-distance.

35 There were sixteen genomic outliers correlated with plant community type (regardless of

36 location).

\section{Conclusions}

38 These findings show that plant community type does not prevent introgression in one

39 subspecies (A. m. raglessi), but low dispersal and habitat heterogeneity could contribute to

40 the maintenance of distinct subspecific morphotypes. Local adaptation in different plant

41 community types could also provide a mechanism for future divergence.

42 Implications

43 We suggest subspecific introgression could increase genetic variation and the adaptive

44 potential of the species, facilitating species persistence under conditions of climate change.

46 Keywords: genotype by sequencing, dispersal, Maluridae, Amytornis, isolation-by-distance, introgression 


\section{Introduction}

Habitat loss is the leading cause of reduced species persistence and species extinction (Bradshaw 2012; Newbold et al. 2015; Allan et al. 2019; Thompson et al. 2019). Within Australia, habitat loss has been anthropogenically driven by a multitude of processes that has changed the landscape notably since the late $18^{\text {th }}$ century. These processes include the introduction of invasive species, anthropogenic dispersal of non-local species, redirection/removal of natural water courses, and changes in soil properties due to agricultural practices (Kingsford 2000; Woinarski et al. 2015; Jellinek et al. 2020; Mallen-Cooper and Zampatti 2020). An alarming proportion of extant species are threatened by habitat loss, and, consequently, have reduced population sizes and limited genetic variation on which selection can act (Saccheri et al. 1998; Amos et al. 2012). Molecular tools are important for conservation management practices and species interventions, as they mediate threats to wildlife and ensure long-term success of intervention programs (Elshire et al. 2011; Steiner et al. 2013; Flockhart et al. 2015; Deiner et al. 2017; Forseth et al. 2017). Population genetics can identify populations that may be in greater need of intervention or better suited for conservation management (Dudgeon et al. 2012; Paparella et al. 2015; Whiteley et al. 2015; Willoughby et al. 2015; Rosauer et al. 2018; Mynhardt et al. 2020; Rossetto et al. 2021). Understanding how species respond to habitat changes is relevant for mitigating future threats, especially where further habitat change is predicted to occur.

Populations may be more likely to cope with climate change if they are able to expand their range and move into novel habitats (Hoffman and Blows 1994). There are several evolutionary dynamics that determine whether a species can expand their range or not. These include how much genetic variation there is at the population margin, the strength of genetic swamping of genotypes from central to marginal individuals, and the heritability of adaptive traits at the population margin (Jenkins and Hoffman 1999; Davis et al. 2013; Moerman et al. 2020). Local adaptation into novel environments at the species boundary is one factor that promotes rangeexpansions, as observed in the European damselfly (Ischnura elegans) (Dudaniec et al. 2018). Gene flow can erode local adaption that may favour range expansion, but if the population is large enough - gene flow could also facilitate local adaptation by 
80 enhancing genetic variation (Kirkpatrick and Barton 1997; Case and Taper 2000). At

81 the leading margin of the European lizard (Zootoca vivipara louislantzi), low gene

82 flow has facilitated a range expansion but low genetic diversity throughout the

83 population could also mean this lizard is susceptible to decline in the face of future

84 climate change (Dupoué et al. 2020). When range-shifts involve secondary contact

85 between divergent taxa, species persistence could also be affected due to loss of

86 locally adaptive traits, hybrid swarms or interspecific competition (Case and Taper

87 2000; Sanchez-Guillen et al. 2016). Conservation of threatened species under future

88 ecological scenarios will depend on the ability to predict range shifts, and an

89 understanding of the genomics of hybridisation and introgression.

90 Associations between populations and their habitat develop through ecological

91 opportunity (Wellborn and Langerhans 2015). For example, morphotypes that give a

92 population an advantage in their particular habitat type are likely to be retained

93 (Aiello et al. 2021; Grismer 2021). The strength of an ecological association will be

94 influenced by the amount of gene flow occurring between populations with different

95 ecological associations, which in turn is dependent on ease of dispersal across the

96 landscape. Individuals are more likely to disperse to habitats that are similar to their

97 habitat of origin. This is because individuals that are locally adapted will have lower

98 fitness outside their original habitat type (Fedorka et al. 2012; Berner and Thibert-

99 Plante 2015). Therefore, populations occurring in linear, unfragmented landscape

100 arrangements, such as habitat gradients, could have reduced gene flow and in turn

101 stronger ecological associations (e.g. Cicero 2004). Populations that occur in

102 landscapes with more diverse patterns of habitat distribution, such as patchy and

103 heterogeneous landscapes, could have greater gene flow because individuals need to

104 disperse greater distances to reach particular habitat types and could therefore choose

105 to remain in an alternate habitat type (Lenormand 2002; Harrisson et al. 2012;

106 Forester et al. 2016). It may be less likely for associations between populations and

107 their habitat to occur in a heterogeneous landscape because gene flow will reduce the

108 frequency of locally selected alleles. More case studies are needed to complement a

109 growing body of theoretical modelling, to inform our understanding of the occurrence

110 of ecological associations and the magnitude of gene flow across different landscape

111 scenarios, ultimately with a view to better manage extant populations. 
112 The endangered thick-billed grasswren (Amytornis modestus, TBGW) is an arid-zone

113 species of the Maluridae family. We adopt the nomenclature of (Black 2011; 2016)

114 which describes seven subspecies of TBGW. There are two extinct and five extant

115 subspecies occurring in parts of the Northern Territory, South Australia and New

116 South Wales (Black et al. 2011; Black and Gower 2017). This taxonomy is a widely

117 accepted (Skroblin and Murphy 2013; Gill and Donsker 2017) however competing

118 taxonomic assignments have been proposed (Christidis et al. 2013; Norman and

119 Christidis 2016). Studies show that A. m. indulkanna and A. m. raglessi are distinct

120 based on morphology and mitochondrial sequences (Austin et al. 2013). These

121 subspecies share a region of parapatry between the salt lakes, Lake Eyre and Lake

122 Torrens that likely formed due to secondary contact and a possible range expansion

123 (Slender et al. 2017). Outside the region of parapatry, the habitat that each subspecies

124 occupies is characterized by a different and distinct plant community (Slender et al.

125 2018a). Within the region of parapatry, there is a third 'sandy' habitat type where

126 grasswrens were rarely present (Slender et al. 2018a). The Central Australian arid

127 zone is known for its heterogeneous distribution of different plant types (Slatyer 1961;

128 Williams 1982; Brandle 1998). This feature, along with the habitat changes associated

129 with grazing in the arid zone (Jessop 1995; Navarro et al. 2006; Facelli and Springbett

130 2009), is likely to impact gene flow between populations associated with particular

131 plant communities. In general, the arid zone is predicted to experience greater

132 temperature extremes, less precipitation, and more extreme weather events in the

133 future (Pickup 1998; Lioubimtseva 2004; Lindenmayer and Burgman 2005; Vaghefi

134 et al. 2019). Adaptability through greater genetic diversity will be critical for the

135 persistence of the two parapatric TBGW subspecies.

136 In this study, we aimed to measure gene flow within and among two TBGW

137 subspecies that have been observed in different plant communities (A. m. indulkanna

138 in plant community A, dominated by Maireana aphylla [cotton saltbush], and A. m.

139 raglessi in plant community $\mathrm{B}$, dominated by $M$. astrotricha [low bluebush] and $M$.

140 pyramidata [blackbush]) (Slender et al. 2018a). The two subspecies may overlap in an

141 area where a third plant community (plant community $\mathrm{AB}$, dominated by Zygochloa

142 paradoxa [sandhill canegrass]) occurs but which is not considered suitable foraging

143 habitat for TBGW (Black et al. 2011; Slender et al. 2018a). This area, the parapatric

144 margin, has been proposed as an area of secondary contact. We examine whether 
145 strength of gene flow changes across the three regions that historically were likely to

146 have been demographically different and today contain different plant community

147 types. We test the idea that gene flow is contemporarily higher in the parapatric

148 margin.

149 Materials and Methods

150 Samples

151 We used DNA from all available TGBW samples which included a combination of

152104 contemporary samples and 14 museum samples (Table S1; supplemental

153 material). Contemporary samples were collected in the field by mist-netting birds

154 during the breeding seasons from 2012 to 2015 . For further details on the study

155 species and contemporary sample collection methods see Slender et al. (2017).

156 Museum samples were collected from two time periods; four museum samples were

157 from 1985 (A. m. raglessi) and the remainder were from 2007 to 2009 (A. m. raglessi

$158[n=2]$ and A. m. indulkanna $[n=8]$ ) (Austin et al. 2013). Samples were organized

159 into three geographically associated zones described in Slender et al. (2017) in order

160 to compare genetic diversity and gene flow between the subspecies centre's and their

161 parapatric margin (Figure 1). Zone AB describes the subspecies parapatric margin;

162 zone A describes the geographic centre of $A$. $m$. indulkanna and occurs to the west of

163 zone $\mathrm{AB}$ and zone $\mathrm{B}$ describes the geographic centre of $A$. m. raglessi and occurs to

164 the east of zone AB. TBGWs in zone A were predominantly found in habitat

165 containing Maireana aphylla (cotton bush) and Atriplex nummularia omissa

166 (Oodnadatta saltbush) (Black et al. 2011; Slender et al. 2018a).While TBGWs in zone

167 B were predominantly found in habitat with $M$. astrotricha (low bluebush) and $M$.

168 pyramidata (blackbush) (Black et al. 2011; Slender et al. 2018a). Zone AB contains

169 shrubs typical of TBGW habitat such as M. astrotricha (low bluebush) and A.

170 vesicaria (bladder saltbush), but this was heterogeneously distributed among stands of

171 Zygochloa paradoxa (sandhill canegrass). The boundary between zone A and zone

$172 \mathrm{AB}$ has been extended compared to Slender et al. (2017) so that two museum samples

173 (SAMA B55668 and SAMA B55667) that were formerly included in zone A, now fall

174 within zone $\mathrm{AB}$. This is because the landscape in this area was more like the habitat

175 of zone AB (Slender et al. 2018a). 
176

177 Genomic DNA was extracted from tissue and blood in salt solution using a DNeasy

178 Blood and Tissue kit (QIAGEN Pty Ltd, VIC, Australia) or a Gentra Puregene Blood

179

180

181

182

183

184

185

186

187

188

189

190

191

192

193

194

195

196

197

198

199

200

201

202

203

204

205

206

\section{DNA extraction}

Kit (QIAGEN Pty Ltd, VIC, Australia). Genomic DNA was extracted from FTA samples following Smith and Burgoyne (2004). DNA extractions were carried out in a separate PCR free laboratory in order to minimise DNA contamination. DNA quantity was measured using the Qubit fluorometer (ThermoFisher Scientific Australia Pty Ltd, VIC, Australia). DNA extractions were quality tested using UVspectrophotometry and agarose gel electrophoresis. Samples were assessed as good quality when they showed 1) a large un-degraded band on an agarose gel and 2) a 260/280 ratio between 1.8 and 2.0 indicating minimal protein and chemical contamination.

\section{Library construction and sequencing}

Genotyping-by-sequencing libraries were generated following the protocol in Poland et al. (2012). DNA samples (200 ng) were digested with $8 \mathrm{U}$ of PstI and MspI at $37^{\circ} \mathrm{C}$ for 2 hrs. Each sample was prepared for multiplexing by ligating a pair of adapters containing a unique barcode to the DNA fragments. We used 96 unique barcodes where the barcodes ranged from 4 to $9 \mathrm{bp}$ (Elshire et al. 2011) to create two pooled libraries. One barcode in each library was assigned as a negative control and seven barcodes in each library were used to duplicate samples within (6 samples) and across (1 sample) libraries. Barcodes were randomly allocated to samples from different geographic locations so that we would detect errors caused by mismatched barcodes that can be made during library preparation or subsequent demultiplexing. We used an adapter mix to DNA ratio of 1:50 ng as this concentration produced libraries with reduced adapter dimer (Elshire et al. 2011). Libraries were then amplified using PCR with the following standard Illumina primers: P5 (5'-

AATGATACGGCGACCACCGAGATCTACAC-3') and P7 (5'CAAGCAGAAGACGGCATACGAGAT-3'). Sequencing was performed on an Illumina next-seq sequencer that produced single end-reads of $62 \mathrm{bp}$ after adapter trimming. Sequencing data was quality checked using FastQC v10.1
(http://www.bioinformatics.babraham.ac.uk/projects/fastqc/). 
207

208

209

210

211

212

213

214

215

216

217

218

219

220

221

222

223

224

225

226

227

228

229

230

231

232

233

234

235

236

237

238

\section{SNP calling and filtering}

Read filtering and SNP calling was performed using STACKS v1.44 (Catchen et al. 2013). Samples were demultiplexed using the process_radtags program and reads from sample replicates were merged into one sample (after preliminary SNP calling with separated duplicates was used to determine error rates). Reads were identified if the adapter barcode (with a maximum of 2 mismatches) and the unique barcode (with a maximum of 1 mismatch) were present. Putative alleles were identified from a stack assembly created with the ustacks program that was instructed to include loci with a minimum depth of coverage of 5 reads, maximum distance of 2 nucleotides, and maximum number of 50 stacks per locus. The cstacks program was used to create a catalog for identifying loci with a maximum of 2 mismatches between putative alleles. SNPs were determined by comparing the output of ustacks with the output of cstacks using the sstacks program. Relaxing the error tolerance rate improves the likelihood of detecting heterozygous calls (Hohenlohe et al. 2010; Lu et al. 2013). We used a bounded model for detecting SNPs with the lower error limit of 0.0001 and an upper error limit of 0.05. Minor alleles with low frequency cause problems in population genetic analyses because they can represent sequencing error and they are not informative population markers (Gonçalves da Silva et al. 2015). We removed loci (1) that were missing calls in more than $80 \%$ of all individuals, or (2) if the minor allele frequency was $<0.05$. An individual was considered heterozygous at a locus if there was a proportion of $<0.75$ reads per allele. We checked that the dyadic likelihood of relatedness did not exceed 0.4 between any individual within zone $\mathrm{A}$ and zone $\mathrm{AB}$ or zone $\mathrm{B}$ and zone $\mathrm{AB}$ using the program COANCESTRY v1.0.1.2 (Wang 2011). A related individual of a pair or group of related individuals was excluded if they were related to more individuals and if they had more missing data.

The output from STACKS consisted of 16,569 loci that we applied additional filtering steps to with a custom script implemented in R STUDIO v1.0.136 (R Core Development Team 2008). Loci were removed if they appeared in the negative control and were observed in less than $85 \%$ of samples. We used a Principal Component Analysis (PCA) in the R package adegenet v2.0.1 (Jombart 2008) to explore preliminary population structure. The putative clusters without admixed individuals were each analysed for loci out of Hardy-Weinberg Equilibrium (HWE) in 
239 the R package pegas v0.9 (Paradis 2010). We removed loci from further analysis that

240 did not conform to HWE in (1) both putative clusters or (2) one putative cluster when

241 a SNP was only present in one cluster. We identified linked loci in each putative

242 cluster excluding potentially admixed individuals, using PLINK v1.07 (Purcell et al.

243 2007). We removed loci from further analysis that were highly correlated $\left(r^{2}>0.1\right)$

244 and had a p-value $<0.01$ in (1) both putative clusters or (2) one putative cluster when a

245 SNP was only present in one cluster. Within a linkage pair, we removed the locus

246 with the most linkage pairs. When both loci had even numbers of linkage pairs, we

247 removed the locus with the most missing data.

248 Differences between putative genetic clusters

$249 \quad F_{S T}$ outlier loci between putatively non-admixed individuals in zone A and zone B

250 were identified using two programs. We ran BAYESCAN v2.1 (Foll and Gaggiotti

251 2008) with default settings after data format conversion with PGDSPIDER v2.1.1.0

252 (Lischer and Excoffier 2012) and the R package OutFLANK v0.1 (Whitlock and

253 Lotterhos 2015). $F_{S T}$ outlier loci were defined as having a $q$-value and corresponding

254 false discovery rate of $<0.1$. Using a consensus list of $F_{S T}$ outlier loci from both

255 analyses, the dataset was separated into three versions, one with neutral loci (n-SNP),

256 one with only outliers putatively under selection (o-SNP), and a third with both

257 neutral and outlier loci (n+o-SNP). The closest known species relative with an

258 available whole genome sequence is the zebra finch (Taeniopygia guttata) (Warren et

259 al. 2010). We performed a discontiguous megablast search that looked for sequence

260 similarities between TBGW o-SNPs and the zebra finch GenBank and refseq

261 assemblies using the blastn and blastx functions respectively with an evalue threshold

262 of $1 \mathrm{e}-6$.

263 To further understand the distribution of shared and distinct genetic variation, we

264 performed an Analysis of Molecular Variance (AMOVA) and calculated the

265 significance of pairwise $F_{\text {ST }}$ between zones using GENODIVE v2.0b27 (Meirmans

266 and Van Tienderen 2004) with 10,000 permutations. We tested differences between

267 genetic clusters in three separate analyses; one where the region of parapatry was

268 merged with zone A, one where the region of parapatry was merged with zone B and

269 the last where zone AB was excluded. We repeated these analyses with the n-SNP

270 dataset and n+o-SNP dataset. Expected heterozygosity $\left(\mathrm{H}_{\mathrm{e}}\right)$ is a measure of genomic 
271 diversity when the dataset consists of SNPs (Fischer et al. 2017). $\mathrm{H}_{\mathrm{e}}$ was calculated

272 for each zone separately using the $n+o-S N P$ dataset.

\section{Isolation-By-Distance}

274 We tested for Isolation-By-Distance (IBD) among eleven sampling localities by

275 calculating geographic and genetic distance matrices that excluded the locality MTB

276 (zone A) as it contained only one individual (Figure 1). The Euclidean distance

277 between localities $(\mathrm{km})$ was first calculated in GENALEX v6.5 (Peakall and Smouse

278 2006; Peakall and Smouse 2012). Any paths between localities that passed through

279 Lake Eyre or Lake Torrens (e.g., MUL and WIT) were corrected so that it did not

280 pass through the salt lake. This was done by calculating the Euclidean distance from

281 the first sampling location to a point in the middle of the space between Lake Eyre

282 and Lake Torrens and then calculating the Euclidean distance between that point and

283 the second sampling location and adding the distances together. All geographic

284 distances between sampling localities were then log transformed to account for

285 individuals moving in two dimensions. We calculated a pairwise $F_{\text {ST }}$ genetic distance

286 matrix with n-SNPs using GENODIVE (Meirmans 2020) and also transformed the

287 genetic data $\left(F_{\mathrm{ST}} / 1-F_{\mathrm{ST}}\right)(\mathrm{Nei} 1977)$. Tests for IBD are easily biased by hierarchical

288 population structure where allele frequencies are sharply divided geographically

289 (Meirmans 2012) as well as uneven sample sizes and the spatial patterns between

290 sampling localities (Balkenhol et al. 2009; Guillot and Rousset 2013; Kierepka and

291 Latch 2015). We therefore performed a series of tests for IBD using three different

292 methods; (1) Mantel and partial Mantel tests, (2) Decomposed Pairwise Regression

293 (DPR), and (3) spatial autocorrelation. To test for limitations in gene flow that might

294 prevent genetic swamping at marginal locations we performed two Mantel tests: (1)

295 across locations within zone A (A. m. indulkanna) and zone AB, and (2) across

296 locations within zone B (A. m. raglessi) and zone AB. We included zone AB in an

297 analysis with either zone because this area appears to be the population margin for

298 both subspecies (the region of parapatry) (Slender et al. 2017). We then performed a

299 partial Mantel test across all zones to test for gene flow among subspecies while

300 accounting for potential population structure across these regions. We used a binary

301 matrix that compared zone $\mathrm{B}$ versus zone $\mathrm{AB}$ and $\mathrm{A}$ combined or zone $\mathrm{A}$ versus zone

302 AB and B combined. We used GENODIVE (Meirmans 2020) to perform mantel and 
303 partial mantel tests with 1000 permutations. DPR is useful for detecting outlier

304 populations that may be associated with weak geographic barriers such as

305 heterogeneous landscapes (Koizumi et al. 2006). We performed a DPR using the R

306 package DPR v1.0 (Reynolds 2011).

307 Finally, we used spatial autocorrelation (Smouse and Peakall 1999) in GenAlEx v6.5

308 to further evaluate spatial structure in the genetic data at an individual level. A

309 pairwise matrix with Roussets's $a$ genetic distance (Rousset 1997; Rousset 2000)

310 between all individuals with the n-SNP dataset was calculated using SPAGeDi v1.4b

311 (Hardy and Vekemans 2002). Geographic distances between individuals were

312 calculated in GenAlEx using the same method to create the geographic distance

313 matrix for the mantel tests. Distance classes were sufficiently small enough to

314 evaluate any non-linear correlations with the autocorrelation coefficient $(r)$ where the

315 sample size within each distance class was relatively even. We looked for the

316 presence of IBD within each distance class as well as the detectability of IBD across

317 multiple distance classes (Diniz-Filho and Pires de Campos Telles 2002). Significance

318 was assessed for both tests using $95 \%$ confidence intervals for the null hypothesis of

319 no spatial structure using 999 random permutations, and for estimates of $r$ by

320 bootstrapping 999 pairwise comparisons for each distance class.

\section{Gene flow}

322 We investigated population structure and admixture using the n-SNP dataset with two

323 methods: (1) Discriminant Analysis of Principal Components (DAPC) (Jombart et al.

324 2010) implemented in the R package adegenet v2.0.1 (Jombart 2008), which assigns

325 individuals to genetic clusters following a PCA while accounting for within-

326 population variation; and (2) Bayesian clustering with the program STRUCTURE

327 v2.3.4 (Pritchard et al. 2000; Falush et al. 2003) that determines genetic clustering

328 based on HWE. All methods are useful for detecting admixed individuals. For the

329 DAPC, we retained one principal component, as this returned the optimum $a$-score,

330 which is the difference between the proportion of successfully reassigned individuals

331 compared to the number of principal components retained. The optimum number for

$332 K$ was inferred from the retained principal component by identifying $K$ where the

333 Bayesian Information Criterion (BIC) produced an elbow in the curve of BIC values

334 as a function of $K$. Admixture was inferred if the proportion of population assignment 
335 was $<0.9$ or $>0.1$ in any individual. For the STRUCTURE analysis, three replicate

336 runs for each $K$ were analysed (as Standard Deviation of $\mathrm{LnP}(\mathrm{K})$ was small) using

337 default settings, unless stated. We used the admixture model with correlated allele

338 frequencies and an MCMC chain of 1,000,000 iterations with a burnin of 10,000

339 iterations to test $K$ between 1 and 5 . To estimate the probability of mixed ancestry for

340 each individual, the option ANCESTDIST was used. Admixture was inferred if the

341 confidence intervals of the individual population assignment did not include 1 or 0 in

342 all three replicate runs. STRUCTURE HARVESTER (Earl and vonHoldt 2011) was

343 used to estimate the best fitting value for $K$. When the highest $\operatorname{LnP}(K)$ was not $K=1$,

344 then the most likely $K$ was determined using Delta $K$ (Evanno et al. 2005). Cluster

345 assignments were merged in CLUMPP v1.1.2 (Jakobsson and Rosenberg 2007) and

346 results were visualized with DISTRUCT v1.1 (Rosenberg 2004). Population

347 assignments of individuals were compared to their mtDNA hapolotype (Slender et al.

348 2017). Further hierarchical population structure was investigated by repeating the

349 analysis on individual populations detected in the initial run (Evanno et al. 2005).

350 Selection

351 Previous comparisons of habitat within the three zones identified three predominant

352 plant communities represented by three principal components (Slender et al. 2018a).

353 We used Latent Factor Mixed Models (LFMMs) (Frichot et al. 2013) to test for

354 associations between genotype ( $\mathrm{n}+\mathrm{o}-\mathrm{SNPs}$ ) and the environmental variables defined

355 by the principal components. The LFMM test was performed in the R package lfmm

356 v0.0.

357 Migration

358 We tested the proportion of migrants between the three zones with a reduced dataset

359 of 200 loci in BAYESASS v3.0.4 (Wilson and Rannala 2003). We performed a PCA

360 with all individuals in the n-SNP dataset with the R package adegenet v2.0.1 (Jombart

3612008 ) and selected loci for use that had the highest loading in the PCA. Three

362 independent MCMC runs were performed with 1,000,000 iterations and a burn-in of

36310,000 iterations. The alpha (allele frequency) and delta (inbreeding coefficient)

364 values were adjusted to 0.6 and 0.4 respectively so that the acceptance rates were

365 between $20 \%$ and $60 \%$. Iterations were sampled every 100 intervals to determine the 
366 posterior distribution of the parameters. Convergence of the MCMC run was assessed

367 by inspecting the trace file in the program TRACER v1.6.0 (Rambaut et al. 2015).

\section{Results}

\section{DNA extraction and sequencing statistics}

370 We used samples from across three zones: zone $\mathrm{A}(n=44)$, zone $\mathrm{B}(n=61)$, and zone

$371 \mathrm{AB}(n=13)$ to assess gene flow between the two parapatric TBGW subspecies.

372 Following DNA extractions, samples stored on FTA® cards produced considerably

373 lower quantities of DNA ( $<500 \mathrm{ng})$ compared to blood stored in salt solution $(>1,000$

374 ng). Following illumina sequencing, the average number of reads per sample (before

375 filtering) was $2,539,005$ with a coefficient of variation of $24.6 \%$. The average

376 between run reproducibility, calculated by determining when the genotype was the

377 same in duplicates on different plates, was $95.7 \%(n=12,192$ loci, excluding missing

378 genotypes). The average within run reproducibility, calculated by determining when

379 the genotype was the same in duplicates on the same plate, was $90.5 \%$ ( $n=146,304$

380 loci, excluding missing genotypes). The average genotyping error rate, calculated

381 from the number of allelic mismatches across duplicates, was $0.31 \%(n=316,992$

382 loci). There were no individuals that exceeded $>30 \%$ missing data; overall the dataset

383 contained 5.56\% missing data. Following SNP calling in STACKS, we removed 5

384 loci that appeared in the negative control and 2929 loci that had low coverage across

385 samples. An initial PCA showed two putative genetic clusters with individuals from

386 zone A forming one cluster, individuals from zone B forming the second cluster and

38719 potentially admixed individuals from zone $\mathrm{AB}$ and zone $\mathrm{B}$ (Figure $\mathrm{S} 1$ ). We

388 observed similar amounts of missing data between the clusters, excluding potentially

389 admixed individuals (cluster 1 [zone A]: 6.41\%, cluster 2 [zone B]: 6.58\%). We

390 removed a further 625 loci from further analysis that did not conform to HWE and

3915428 loci that could potentially introduce linkage disequilibrium.

\section{Subspecies variation}

393 The proportion of heterozygous SNPs per sample varied from 0.234 in a sample from

394 zone A to 0.301 in samples from both zone A and zone B. Mean \pm SE estimates of

395 heterozygosity (He) were slightly higher for zone A and zone B compared to zone AB

396 (zone $\mathrm{A}=0.303 \pm 0.002$, zone $\mathrm{B}=0.304 \pm 0.001$; zone $\mathrm{AB}=0.288 \pm 0.002$ ). The 
397 number of private alleles within zone B was greater $(n=16)$ than for either zone A $(n$

$398=1)$ or zone $\mathrm{AB}(\mathrm{n}=0)$. We identified 39 loci as potential $F_{S T}$ outliers under selection 399 which left 7543 loci that were treated as neutral loci not under selection. Therefore,

400 the dataset o-SNP contained 39 loci and the dataset n-SNP contained 7543 loci. Of the

40139 outlier loci, nine loci were monomorphic in zone $\mathrm{A}$; three loci were monomorphic

402 in zone $\mathrm{B}$ and four were monomorphic in zone AB. Of the four monomorphic loci in

403 zone $\mathrm{AB}$, three were shared with the monomorphic outliers of zone $\mathrm{A}$ and one was

404 shared with the monomorphic outliers of zone B. Four outliers had hits to nucleotide

405 sequences from the zebra finch GenBank assembly (Table S2) but there were no

406 matches to protein sequences from the refseq assembly. These blast hits did not reveal

407 why there could be associations between outlier loci and plant community type.

408 Zone B had slightly more polymorphic loci in the n-SNP dataset (99.9\%) compared to

409 zone A (99.2\%). Using the n-SNP dataset, the proportion of total genetic variance was

410 shared among individuals and populations similarly when the region of parapatry

411 (zone $\mathrm{AB}$ ) was combined with either zone $\mathrm{A}$ or zone $\mathrm{B}$, or even when it was excluded

412 (Table 1). The proportion of variance in the case of n-SNP was greater among

413 individuals (mean $0.080 \%, p<0.001$ ) than among populations ( mean $0.008 \%, p<$

4140.001 ; (Table 1). Using the $\mathrm{n}+\mathrm{o}-\mathrm{SNP}$ dataset, the proportion of total genetic variance

415 explained by population was greater than that explained among individuals for all

416 three tests $(A+A B \vee B, B+A B \vee A, A \vee B)$. This difference was greatest when zone

$417 \mathrm{AB}$ was excluded. When zone $\mathrm{AB}$ was not excluded the difference was greater when

418 combined with zone B (among individuals $=0.185 \%, p<0.001$; among individuals $=$

$4190.094 \%, p<0.001)$. Using the n-SNP dataset, there was no difference in pairwise

420 estimates of $F_{\mathrm{ST}}$ when the region of parapatry was combined with either zone A or

421 zone B (Table 2). The pairwise estimates of $F_{\mathrm{ST}}$ using n+o-SNP was higher when

422 zone $\mathrm{AB}$ was combined with zone $\mathrm{B}(0.202, p<0.001)$ compared to when zone $\mathrm{AB}$

423 was combined with zone A $(0.165, p<0.001$; Table 2$)$.

424 Isolation-By-Distance

425 IBD was detected in only one Mantel test that included localities from zone A and 426 zone $\mathrm{AB}\left(\mathrm{R}^{2}=0.112, \mathrm{Rxy}=0.335, p=0.029\right)$ (Figure $\left.\mathrm{S} 2\right)$. There was no correlation 427 between genetic and geographic distance across localities from zone B and zone AB $428\left(\mathrm{R}^{2}=0.012, \mathrm{Rxy}=0.110, p=0.435\right)$. However, this result may have been affected by 
429 the small number of localities used in this test (Figure S2). Partial Mantel tests across

430 all zones where zone $\mathrm{AB}$ was in the same cluster as A or B were significant (zone

$431 \mathrm{~A}+\mathrm{AB}$ vs $\mathrm{B} ; \mathrm{R}^{2}=0.317$, Rxy (spearman's $\mathrm{r}$ ) $=0.514, p=0.001$ and zone $\mathrm{B}+\mathrm{AB}$ vs $\mathrm{A}$;

$432 \mathrm{Rxy}=0.385, p=0.015$ ) (Figure 2). The sample sizes for the spatial autocorrelation

433 were skewed for the lowest distance class (0-20 kms) but for all other distance classes

434 the sample size was on average ( \pm SD) $293 \pm 132$. This analysis showed that an

435 individual level there was positive spatial autocorrelation for the first two distance

436 classes (0-20 and 20-40 kms) (Figure 3). When plotting $r$ as a function of increasing

437 distance classes, the curve intercepted the $x$-axis at $123.6 \mathrm{kms}$ (Figure 3). IBD was

438 detectible from $0-60 \mathrm{~km}$ and between 80-100 and 140-160 km $(p<0.01)$. This

439 suggests that spatial autocorrelation is linear up to $60 \mathrm{kms}$ and non-linear at other

440 intervals, which may indicate a pattern of low habitat connectivity. Initial results of

441 the DPR analysis suggested that there were no populations that had greater divergence

442 than what was expected based on distance alone. The model with the smallest $\mathrm{AIC}_{\mathrm{C}}$

443 where $\mathrm{R}^{2}$ was also the highest and where $\Delta \mathrm{AIC}_{\mathrm{C}}<2$ was for 3 sub-populations

444 (OOW, MTL, and MUR) to be potential outliers however this was not significant

445 (Table 3). Regression of all sub-populations with all other sub-populations also

446 suggested genetic drift and gene flow were in equilibrium and no population structure

447 was present.

448 Geneflow

449 A PCA showed limited population structure between zone A and B along the first 450 component (1.7\% of variation) as there was no separation of individuals into clusters

451 (Figure 4). Despite this, STRUCTURE identified two major genetic clusters (Table

452 S3) corresponding to eastern and western populations. Two genetic clusters were also

453 identified by the DAPC analysis albeit with weaker support (Figure S3). Using $K=2$,

454 results from both STRUCTURE and the DAPC were concordant in that both analyses

455 showed that 1) zone $\mathrm{AB}$ contained the highest proportion of admixed individuals 2)

456 there were greater proportions of admixture in individuals in zone $A B$ than either

457 zone $\mathrm{A}$ or zone $\mathrm{B}$, and 3 ) there were greater proportions of admixture in individuals in

458 zone B than in zone A (Figure 5). Comparison of the two methods showed there were

459 discrepancies in the identity of admixed individuals as well as in the proportions of

460 admixture. The DAPC method compromises the power for detecting admixture with 
461 the assignment of individuals to populations, therefore we have limited the discussion

462 of admixture below to the STRUCTURE results. In zone A, 2.3\% of individuals were

463 admixed and these individuals had a relatively low proportion of assignment

464 probability from the eastern genetic cluster $(<18 \%)$. In zone B, $18 \%$ of individuals

465 were admixed and these individuals had low to high proportions of assignment

466 probability from the western genetic cluster $(18.7-52.0 \%)$. Two of the admixed

467 individuals in zone B came from museum samples that were either collected in 1985

468 or 2007 and were from localities furthest from the region of parapatry (MUR and

469 MTL). In zone $\mathrm{AB}$, all individuals were admixed and had low to high levels of

470 assignment probability from both the eastern (17.5 - 71.4\%) and western genetic

471 clusters $(28.6-82.5 \%)$. To look at hierarchical substructure within the identified

472 populations, individuals in zone $\mathrm{B}$ and then zone $\mathrm{A}$ were excluded from two separate

473 STRUCTURE analyses. For zone $\mathrm{A}$ and zone $\mathrm{AB}, K=1$ was the most likely using

474 mean $\operatorname{LnP}(K)$ and for zone B and zone $\mathrm{AB}, K=3$ was most likely using Delta $K$

475 (Figure S4). Two of smaller clusters from the zone B and zone AB analysis comprised

476 of groups of individuals that were from the same or neighbouring territories and had

477 slightly higher levels of relatedness. An earlier analysis with COANCESTRY showed

478 that the Dyadic likelihood and the 95\% confidence intervals for those groups were: $r$

$479=0.28(0.26,0.30)-0.30(0.28,0.32)$ for three individuals in the first cluster and $r=$

$4800.14(0.12,0.16)-0.28(0.25,0.30)$ for seven individuals in the second cluster. The

481 three individuals in first cluster were also separated along component two (PC2; 1.4\%

482 variance) of the PCA (Figure 4).

483 Ecological associations and migration

484 A unique plant community was previously identified in each of the three zones using 485 a PCA reported in Slender et al. (2018a). PC1 was associated with low abundance of 486 Atriplex vesicaria and high abundance of Zygochloa paradoxa and was predominant 487 in Zone AB. PC2 was associated with high abundance of Maireana aphylla and low 488 abundance of M. astrotricha and M. pyramidata and was predominant in Zone A. PC3 489 was associated with low abundance of A. nummularia omissa and high abundance of 490 Acacia spp and Rhagodia spinescens and was predominant in Zone B (Table S4).

491 Using $K=2$ output from structure, the LFMM analysis identified 328, 333 and 419

492 loci associated with PC1, PC2 and PC3 respectively. Of the $39 F_{\mathrm{ST}}$ outliers, there 
493 were 12 loci that correlated with PC2 (two of these also correlated with PC3) and six

494 loci that correlated with PC3. No loci were found to correlate to PC1. The results

495 from BAYESASS suggested that zone AB received more migrants per generation

496 than zone A or zone B (Figure 6). Zone AB received more migrants per generation

497 from zone $\mathrm{A}$ than zone $\mathrm{B}$; the mean $\pm \mathrm{SD}$ migration from zone $\mathrm{A}=21.0 \pm 4.7 \%$ and

498 from zone $\mathrm{B}=10.3 \pm 4.6 \%$. Zone $\mathrm{B}$ received some migration per generation from

499 zone A $(4.5 \pm 1.6 \%)$, but zone A received $<1 \%$ migration per generation from either

500 zone B or zone $\mathrm{AB}$.

501 Discussion

502 This study aimed to measure patterns of genetic diversity between the parapatric

503 margin (zone AB) of two TBGW subspecies, and their population centre's (A. m.

504 raglessi $=$ zone $\mathrm{B}$ and $A$. $m$. indulkanna = zone A). Greater genetic variation at the

505 margin could increase the potential for local adaptation to occur in different

506 vegetation types at the margin. We detected gene flow occurring between the

507 subspecies that was not restricted to zone $\mathrm{AB}$ as was previously thought and observed

508 no evidence for greater diversity in zone AB compared to other zones. We discovered

509 a pattern of IBD across the subspecies, low genotypic evenness and low genetic

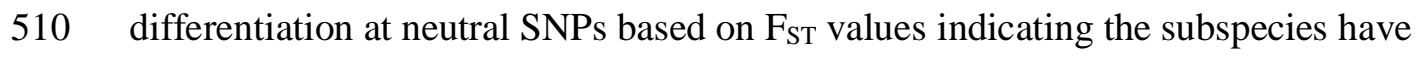

511 introgressed considerably. Spatial autocorrelation at short distances suggests that IBD

512 is likely caused by short-range dispersal. We detected more migration between the

513 parapatric margin and the population centre of $A$. $m$. raglessi suggesting introgression

514 was asymmetric towards A. $m$. raglessi. There was evidence of local adaptation in

515 both subspecies to different plant communities, which suggests selection could lead to

516 future differentiation of the subspecies.

517 IBD increases genetic variation because it occurs when there is low gene flow

518 between distant locations. The presence of IBD indicates that individuals within a

519 population only disperse short distances (Aguillon et al. 2017). Grasswrens are

520 thought to have poor dispersal ability due to their small size and short wings and have

521 highly localized taxonomies (Christidis et al. 2010; Austin et al. 2013). This study

522 found evidence for IBD across the TBGW subspecies, A. m. raglessi and A. $m$.

523 indulkanna, which have been geographically isolated in the past and have

524 subsequently made secondary contact (Austin et al. 2013; Slender et al. 2017). The 
525 population structure demonstrated in this study is likely biased by the presence of

526 IBD, as limited sampling across large areas replicates patterns of population structure

527 (Perez et al. 2018). Poor dispersal is likely to be one mechanism that has created IBD

528 between these subspecies; however, we also detected patterns suggesting landscape

529 heterogeneity could influence gene flow strength. Further work could assess

530 landscape effects on gene flow strength (van Strien et al. 2015).

531 IBD in this study indicates considerable nuclear introgression between the subspecies

532 and a low risk of outbreeding depression (Frankham 2010). Introgression may have

533 ensued over a long period of time if secondary contact between A. m. indulkanna and

534 A. m. raglessi occurred a long time ago. Alternatively, there may be a preference for

535 heterospecific mates which could also have led to increased introgression. We

536 previously found that $A$. $m$. indulkanna more often and more intensely responded to

537 hetero-subspecific song than con-subspecific song (Slender et al. 2018b). While we

538 know little about the function of grasswren song, it is plausible that greater response

539 to song could indicate mating preferences (Nowicki and Searcy 2005). Introgression

540 of taxonomically young lineages such as subspecies could increase their genetic

541 diversity and the adaptive potential (Grant and Grant 2019). Acknowledging

542 populations that interbreed for conservation planning is a useful component of

543 biodiversity management strategy that is gaining traction in conservation programs

544 (Chan et al. 2019). This stands in contrast to previous concerns that introgression is a

545 threat to biodiversity such as when anthropogenic interference creates conditions that

546 promote species collapse via hybridisation (Allendorf et al. 2001). Conservation

547 approaches need to evaluate the role of hybridisation between populations and species

548 as increased genetic variation may be supported by introgression (Bohling 2016).

549 Subspecies classifications have a major impact on the allocation of conservation

550 resources (Zink 2004). Both A. m. raglessi and A. m. indulkanna are currently

551 classified as subspecies based on plumage and morphological differences, and a

552 mitochondrial divergence of 1.7\% at ND2 (Black 2011; Austin et al. 2013). However,

553 these subspecies are also known to have a continuous distribution and mitochondrial

554 paraphyly (Slender et al. 2017). The lack of genetic differentiation and high level of

555 gene flow between A. m. raglessi and A. m. indulkanna suggests these subspecies

556 could be lumped into one Evolutionarily Significant Unit (ESU) for conservation 
557 purposes (Moritz 1994; Zink 2004). However, clinal genetic variation caused by IBD

558 indicates subspecies classifications that require separate management approaches

559 tailored specifically to A. m. raglessi or A. m. indulkanna. Other studies show that

560 phenotypic variation moderately correlates with genotypic variation in natural

561 populations (Wood et al. 2021). This supports the argument that morphologically

562 divergent populations make a significant contribution to biodiversity. Managing the

563 genetic variation captured by each of these subspecies will enable greater adaptive

564 potential in the future (Fraser and Bernatchez 2001; Coates et al. 2018). Gene flow

565 and genetic variation have an integral role in conservation management of subspecies,

566 and sometimes units defined by morphotype is appropriate.

567 Speciation was traditionally thought to be more commonly associated with population

568 divergence in allopatry, which has affected how we define species and subspecies

569 (particularly those not in allopatry) (De Queiroz 2007; Marie Curie Speciation

570 Network 2012). Examples where populations have undergone divergence with gene

571 flow are now becoming more common since genomic techniques to assess gene flow

572 are more accessible (Sousa and Hey 2013; Seehausen et al. 2014; Toews et al. 2016).

573 This study shows that A. m. raglessi and A. m. indulkanna display patterns of

574 morphological divergence that are in congruence with outlier loci associated with the

575 subspecies occurrence in different vegetation types. This pattern is similar to other

576 models of divergence with gene flow such as the little greenbul (Andropadus virens)

577 where morphological divergence is more likely explained by the birds occurrence in

578 different habitat types (savanna versus forest or mountain versus forest) than their

579 allopatic history (Smith et al. 2005). In another model of divergence with gene flow

580 (Littorina saxatilis), outlier loci have been genomically linked with loci that control

581 phenotype, which are selected for according to ecotype (Hollander et al. 2015).

582 Lastly, Haenel et al. (2021) show how populations of the threespine stickleback fish

583 (Gasterosteus aculeatus) that possess phenotypes associated with either stream or lake

584 environments have developed reproductive isolation without any form of geographic

585 barrier. This research outlines a mechanism for divergence with gene flow and

586 suggests that the two parapatric TBGW subspecies in this study could be a model of

587 divergence with gene flow that may continue to diverge in the future. 
588 This study detected two interesting genomic patterns, the cause of which remain

589 unresolved. Mitochondrial paraphyly at ND2 detected by Slender et al. (2017)

590 predicted a low rate of genomic introgression as only $10 \%$ of $A$. m. raglessi

591 individuals had an A. m. indulkanna haplotype. The contradictory results of this study

592 based on nuclear markers could be explained by a number of processes, for example,

593 selection for particular mtDNA haplotypes (Toews and Brelsford 2012; Morales et al.

594 2015; Morales et al. 2018), or greater dispersal of males compared to females. Other

595 malurid species are known to display female sex-biased dispersal (Cockburn et al.

596 2003). However, the adult sample size per sex in this study was too small to

597 investigate sex-biased dispersal. Intriguingly, this study also detected a third cluster of

598 individuals in the middle of the A. m. raglessi range that displayed unique genomic

599 variation. We can only hypothesize why these individuals were identified as distinct,

600 but one possible scenario may be that limited gene flow between $A$. m. raglessi and

601 another TBGW subspecies, such as A. m. curnamona, could be occurring or has more

602 likely occurred in the past. The location of the nearest A. m. curnamona sighting is

603 less than $100 \mathrm{~km}$ southeast from an A. m. raglessi sighting (Black et al. 2010). Further

604 sampling of adult grasswrens and the inclusion of samples from other grasswren

605 subspecies may reveal patterns of sex-biased dispersal and explain the source of

606 distinct genomic variation detected within the A. m. raglessi population.

607 TBGW subspecies show asymmetric gene flow from A. m. indulkanna to A. $m$.

608 raglessi. The dune field that runs between Lake Eyre and Lake Torrens demarcates

609 the boundary of the asymmetry (Slender et al. 2017). Asymmetric gene flow could

610 occur as the result of several processes, such as greater niche breadth in A. $m$.

611 indulkanna, demographic or ecological differences on either side of the dune field that

612 promote greater geneflow from A. m. indulkanna to A. m. raglessi (e.g. Oswald et al.

613 2017), or a mating advantage for A. m. indulkanna (e.g. Baldassarre and Webster

614 2013; Baldassarre et al. 2014; Slender et al. 2018b). The more frequent and intense

615 response of $A$. m. indulkanna towards hetero-subspecific song compared to con-

616 subspecific song could suggest A. m. indulkanna is more competitive than A. $m$.

617 raglessi. A. m. raglessi did not show the same strength of response to hetero-

618 subspecific song compared to con-subspecific song (Slender et al. 2018b). Further

619 work is needed to test hypotheses regarding subspecies behaviour and habitat 
620 preference, landscape ecological productivity and stability, and mito-nuclear

621 incompatibilities.

622 This study shows that two parapatric TBGW subspecies introgressed and that gene

623 flow is asymmetric towards $A$. m. raglessi. Gene flow between the subspecies is

624 limited by distance probably due to the low dispersing ability of the species as well as

625 landscape heterogeneity. We suggest that these subspecies should be taxonomically

626 (and administratively) managed as distinct units despite considerable introgression.

627 Plant community type does not appear to limit geneflow nor does it provide a

628 mechanism for increased genetic diversity at the parapatric margin as was predicted.

629 However, adaptation to different plant community types suggests divergence with

630 gene flow could be a pathway towards increased genomic variation in the future. This

631 study provides an Australian arid zone example to show that gene flow between

632 subspecies can increase genetic variation within a species. Increased gene flow is

633 expected to facilitate persistence of the species through enhanced adaptive capacity.

634 Populations that contain distinct genomic variation should be managed separately

635 particularly in environments that are likely to be affected by future climate change.

\section{Data availability statement}

637 The data that support this study will be shared upon reasonable request to the

638 corresponding author.

639 Conflicts of Interest

640 The authors declare no conflicts of interest

\section{Declaration of Funding}

642 This research would not have been possible without funding contributions from the

643 Nature Foundation of South Australia. We also acknowledge the generous financial

644 support from the Nature Conservation Society of South Australia, Birds SA

645 Conservation Fund, Royal Society of South Australia, Birdlife Australia and the Field

646 Naturalists of South Australia. These supporting sources were not involved in the

647 preparation of the data or manuscript or decision to submit the manuscript for

648 submission. 
649

650

651

652

653

654

655

656

657

658

659

660

661

662

663

664

665

666

667

668

669

670

671

672

673

674

675

676

677

678

679

680

\section{Acknowledgements}

This research was conducted under the approval from the Department for

Environment and Water who has also supplied the mapping vectors used in Figure 1.

We thank the pastoral landowners and Arrium mining for access to their properties.

We thank Dr. Andrew Black for advice on research outcomes and for insightful discussions about grasswren evolution and ecology. We thank Dr. Valeria Zanollo and all the volunteers that helped with data collection.

\section{References}

Aguillon, S. M., Fitzpatrick, J. W., Bowman, R., Schoech, S. J., Clark, A. G., Coop, G., and Chen, N. (2017). Deconstructing isolation-by-distance: The genomic consequences of limited dispersal. PLoS Genetics 13(8), e1006911.

Aiello, B. R., Tan, M., Bin Sikandar, U., Alvey, A. J., Bhinderwala, B., Kimball, K. C., Barber, J. R., Hamilton, C. A., Kawahara, A. Y., and Sponberg, S. (2021).

Adaptive shifts underlie the divergence in wing morphology in bombycoid moths. Proceedings of the Royal Society B: Biological Sciences 288(1956), 20210677.

Allan, J. R., Watson, J. E. M., Di Marco, M., O'Bryan, C. J., Possingham, H. P., Atkinson, S. C., and Venter, O. (2019). Hotspots of human impact on threatened terrestrial vertebrates. PLoS Biol 17(3), e3000158.

Allendorf, F. W., Leary, R. F., Spruell, P., and Wenburg, J. K. (2001). The problems with hybrids: setting conservation guidelines. Trends in Ecology and Evolution 16(11), 613-622.

Amos, J. N., Bennett, A. F., Mac Nally, R., Newell, G., Pavlova, A., Radford, J. Q., Thomson, J. R., White, M., and Sunnucks, P. (2012). Predicting landscape-genetic consequences of habitat loss, fragmentation and mobility for multiple species of woodland birds. Plos One 7(2), e30888.

Austin, J. J., Joseph, L., Pedler, L. P., and Black, A. B. (2013). Uncovering cryptic evolutionary diversity in extant and extinct populations of the southern Australian arid zone Western and Thick-billed Grasswrens (Passeriformes: Maluridae: Amytornis). Conservation Genetics 14(6), 1173-1184.

Baldassarre, D. T., and Webster, M. S. (2013). Experimental evidence that extra-pair mating drives asymmetrical introgression of a sexual trait. Proceedings of the Royal Society of London. Series B: Biological Sciences 280(1771), 20132175. 
681 Baldassarre, D. T., White, T. A., Karubian, J., and Webster, M. S. (2014). Genomic

682 and morphological analysis of a semipermeable avian hybrid zone suggests

683 asymmetrical introgression of a sexual signal. Evolution 68(9), 2644-2657.

684 Balkenhol, N., Waits, L. P., and Dezzani, R. J. (2009). Statistical approaches in

685 landscape genetics: an evaluation of methods for linking landscape and genetic data.

686 Ecography 32(5), 818-830.

687 Berner, D., and Thibert-Plante, X. (2015). How mechanisms of habitat preference

688 evolve and promote divergence with gene flow. J Evol Biol 28(9), 1641-1655.

689 Black, A. (2011). Subspecies of the Thick-billed Grasswren Amytornis modestus

690 (Aves-Maluridae). Transactions of the Royal Society of South Australia 135(1), 26-

69138.

692 Black, A. (2016). Reappraisal of plumage and morphometic diversity in Thick-billed

693 Grasswren Amytornis modestus (North, 1902), with description of a new subspecies.

694 Bulletin of the British Ornithologists Club 136(1), 58-68.

695 Black, A., and Gower, P. (2017). 'Grasswrens: Australian outback identities.' (Axiom:

696 Stepney, South Australia.)

697 Black, A., Joseph, L., Pedler, L., and Carpenter, G. A. (2010). A taxonomic

698 framework for interpreting evolution within the Amytornis textilis-modestus complex

699 of grasswrens. Emu - Austral Ornithology 110(4), 358-363.

700 Black, A. B., Carpenter, G. A., and Pedler, L. P. (2011). Distribution and habitats of

701 the Thick-Billed Grasswren Amytornis modestus and comparison with the Western

702 Grasswren Amytornis textilis myall in South Australia. South Australian Ornithologist

703 37(2), 60-80.

704 Bohling, J. H. (2016). Strategies to address the conservation threats posed by

705 hybridization and genetic introgression. Biological Conservation 203, 321-327.

706 Bradshaw, C. J. A. (2012). Little left to lose: deforestation and forest degradation in

707 Australia since European colonization. Journal of Plant Ecology 5(1), 109-120.

708 Brandle, R. (1998) A biological survey of the Stony Deserts, South Australia, 1994-

709 1997. Heritage and Biodiversity Section, Department for Environment, Heritage and

710 Aboriginal Affairs, South Australia.

711 Case, T. J., and Taper, M. L. (2000). Interspecific competition, environmental

712 gradients, gene flow, and the coevolution of species' borders. The American

713 Naturalist 155(5), 583-605. 
714 Catchen, J., Hohenlohe, P. A., Bassham, S., Amores, A., and Cresko, W. A. (2013).

715 Stacks: an analysis tool set for population genomics. Molecular Ecology 22(11),

716 3124-3140.

717 Chan, W. Y., Hoffmann, A. A., and Oppen, M. J. H. (2019). Hybridization as a

718 conservation management tool. Conservation Letters 12(5).

719 Christidis, L., Rheindt, F. E., Boles, W. E., and Norman, J. A. (2010). Plumage

720 patterns are good indicators of taxonomic diversity, but not of phylogenetic affinities,

721 in Australian grasswrens Amytornis (Aves: Maluridae). Molecular Phylogenetics and

722 Evolution 57(2), 868-877.

723 Christidis, L., Rheindt, F. E., Boles, W. E., and Norman, J. A. (2013). A re-appraisal

724 of species diversity within the Australian grasswrens Amytornis (Aves: Maluridae).

725 Australian Zoologist 36(4), 429-437.

726 Cicero, C. (2004). Barriers to sympatry between avian sibling species (Paridae:

727 Baeolophus) in local secondary contact. Evolution 58(7), 1573-1587.

728 Coates, D. J., Byrne, M., and Moritz, C. (2018). Genetic Diversity and Conservation

729 Units: Dealing With the Species-Population Continuum in the Age of Genomics.

$730 \quad$ Frontiers in Ecology and Evolution 6.

731 Cockburn, A., Osmond, H. L., Mulder, R. A., Green, D. J., and Double, M. C. (2003).

732 Divorce, dispersal and incest avoidance in the cooperatively breeding superb fairy-

733 wren Malurus cyaneus. Journal of animal ecology 72, 189-202.

734 Davis, J. M. P., van Heerwaarden, B., Sgrò, C. M., Donald, J. A., and Kemp, D. J.

735 (2013). Low genetic variation in cold tolerance linked to species distributions in

736 butterflies. Evolutionary Ecology 28(3), 495-504.

737 De Queiroz, K. (2007). Species concepts and species delimitation. Systematic Biology

$738 \quad \mathbf{5 6}(6), 879-886$.

739 Deiner, K., Bik, H. M., Machler, E., Seymour, M., Lacoursiere-Roussel, A.,

740 Altermatt, F., Creer, S., Bista, I., Lodge, D. M., de Vere, N., Pfrender, M. E., and

741 Bernatchez, L. (2017). Environmental DNA metabarcoding: Transforming how we

742 survey animal and plant communities. Mol Ecol 26(21), 5872-5895.

743 Diniz-Filho, J. A. F., and Pires de Campos Telles, M. (2002). Spatial autocorrelation

744 analysis and the identification of operational units for conservation in continuous

745 populations. Conservation Biology 16(4), 924-935. 
746 Dudaniec, R. Y., Yong, C. J., Lancaster, L. T., Svensson, E. I., and Hansson, B.

747 (2018). Signatures of local adaptation along environmental gradients in a range-

748 expanding damselfly (Ischnura elegans

749 ). Molecular Ecology 10.1111/mec.14709.

750 Dudgeon, C. L., Blower, D. C., Broderick, D., Giles, J. L., Holmes, B. J., Kashiwagi,

751 T., Kruck, N. C., Morgan, J. A., Tillett, B. J., and Ovenden, J. R. (2012). A review of

752 the application of molecular genetics for fisheries management and conservation of

753 sharks and rays. J Fish Biol 80(5), 1789-1843.

754 Dupoué, A., Trochet, A., Richard, M., Sorlin, M., Guillon, M., Teulieres $\square$ Quillet, J.,

755 Vallé, C., Rault, C., Berroneau, M., Berroneau, M., Lourdais, O., Blaimont, P.,

756 Bertrand, R., Pottier, G., Calvez, O., Guillaume, O., Le Chevalier, H., Souchet, J., Le

757 Galliard, J. F., Clobert, J., Aubret, F., and Razgour, O. (2020). Genetic and

758 demographic trends from rear to leading edge are explained by climate and forest

759 cover in a cold $\square$ adapted ectotherm. Diversity and Distributions 27(2), 267-281.

760 Earl, D. A., and vonHoldt, B. M. (2011). STRUCTURE HARVESTER: a website and

761 program for visualizing STRUCTURE output and implementing the Evanno method.

762 Conservation Genetics Resources 4(2), 359-361.

763 Elshire, R. J., Glaubitz, J. C., Sun, Q., Poland, J. A., Kawamoto, K., Buckler, E. S.,

764 and Mitchell, S. E. (2011). A robust, simple genotyping-by-sequencing (GBS)

765 approach for high diversity species. PLoS One 6(5), e19379.

766 Evanno, G., Regnaut, S., and Goudet, J. (2005). Detecting the number of clusters of

767 individuals using the software STRUCTURE: a simulation study. Molecular Ecology

768 14(8), 2611-2620.

769 Facelli, J. M., and Springbett, H. (2009). Why do some species in arid lands increase

770 under grazing? Mechanisms that favour increased abundance of Maireana pyramidata

771 in overgrazed chenopod shrublands of South Australia. Austral Ecology 34(5), 588-

772597.

773 Falush, D., Stephens, M., and Pritchard, J. K. (2003). Inference of population

774 structure using multilocus genotype data: linked loci and correlated allele frequencies.

775 Genetics 164, 1567-1587.

776 Fedorka, K. M., Winterhalter, W. E., Shaw, K. L., Brogan, W. R., and Mousseau, T.

777 A. (2012). The role of gene flow asymmetry along an environmental gradient in

778 constraining local adaptation and range expansion. Journal of Evolutionary Biology

779 25(8), 1676-1685. 
780 Fischer, M. C., Rellstab, C., Leuzinger, M., Roumet, M., Gugerli, F., Shimizu, K. K.,

781 Holderegger, R., and Widmer, A. (2017). Estimating genomic diversity and

782 population differentiation - an empirical comparison of microsatellite and SNP

783 variation in Arabidopsis halleri. BMC Genomics 18(1), 69.

784 Flockhart, D. T., Pichancourt, J. B., Norris, D. R., and Martin, T. G. (2015).

785 Unravelling the annual cycle in a migratory animal: breeding-season habitat loss

786 drives population declines of monarch butterflies. J Anim Ecol 84(1), 155-165.

787 Foll, M., and Gaggiotti, O. (2008). A genome-scan method to identify selected loci

788 appropriate for both dominant and codominant markers: a Bayesian perspective.

789 Genetics 180(2), 977-993.

790 Forester, B. R., Jones, M. R., Joost, S., Landguth, E. L., and Lasky, J. R. (2016).

791 Detecting spatial genetic signatures of local adaptation in heterogeneous landscapes.

792 Mol Ecol 25(1), 104-120.

793 Forseth, T., Barlaup, B. T., Finstad, B., Fiske, P., Gjøsæter, H., Falkegård, M.,

794 Hindar, A., Mo, T. A., Rikardsen, A. H., Thorstad, E. B., Vøllestad, L. A., Wennevik,

795 V., and Gibbs, M. (2017). The major threats to Atlantic salmon in Norway. ICES

796 Journal of Marine Science 74(6), 1496-1513.

797 Frankham, R. (2010). Challenges and opportunities of genetic approaches to

798 biological conservation. Biological Conservation 143(9), 1919-1927.

799 Fraser, D. J., and Bernatchez, L. (2001). Adaptive evolutionary conservation: towards

800 a unified consept for defining conservation units. Molecular Ecology 10, 2741-2752.

801 Frichot, E., Schoville, S. D., Bouchard, G., and François, O. (2013). Testing for

802 associations between loci and environmental gradients using latent factor mixed

803 models. Mol Biol Evol 30(7), 1687-1699.

804 Gill, F., and Donsker, D. (2017) 'IOC World Bird List.' Version 7.3. In Available at

805 http://www.worldbirdnames.org/ [Verified 19 Sep 2017]

806 Gonçalves da Silva, A., Barendse, W., Kijas, J. W., Barris, W. C., McWilliam, S.,

807 Bunch, R. J., McCullough, R., Harrison, B., Hoelzel, A. R., and England, P. R.

808 (2015). SNP discovery in nonmodel organisms: strand bias and base-substitution

809 errors reduce conversion rates. Molecular Ecology Resources 15(4), 723-736.

810 Grant, P. R., and Grant, B. R. (2019). Hybridization increases population variation

811 during adaptive radiation. Proc Natl Acad Sci U S A 116(46), 23216-23224. 
812 Grismer, L. L. (2021). Comparative ecomorphology of the sandstone night lizard

813 (Xantusia gracilis) and the granite night lizard (Xantusia henshawi). Vertebrate

814 Zoology 71, 425-437.

815 Guillot, G., and Rousset, F. (2013). Dismantling the Mantel tests. Methods in Ecology

816 and Evolution 4(4), 336-344.

817 Haenel, Q., Oke, K. B., Laurentino, T. G., Hendry, A. P., and Berner, D. (2021).

818 Clinal genomic analysis reveals strong reproductive isolation across a steep habitat

819 transition in stickleback fish. Nat Commun 12(1), 4850.

820 Hardy, O. J., and Vekemans, X. (2002). SPAGeDi: a versatile computer program to

821 analyse spatial genetic structure at the individual or population levels. Molecular

822 Ecoloty Notes 2, 618-620.

823 Harrisson, K. A., Pavlova, A., Amos, J. N., Takeuchi, N., Lill, A., Radford, J. Q., and

824 Sunnucks, P. (2012). Fine-scale effects of habitat loss and fragmentation despite

825 large-scale gene flow for some regionally declining woodland bird species.

826 Landscape Ecology 27(6), 813-827.

827 Hoffman, A. A., and Blows, M. W. (1994). Species borders: ecological and

828 evolutionary perspectives. Trends in Ecology and Evolution 9(6), 223-227.

829 Hohenlohe, P. A., Bassham, S., Etter, P. D., Stiffler, N., Johnson, E. A., and Cresko,

830 W. A. (2010). Population genomics of parallel adaptation in threespine stickleback

831 using sequenced RAD tags. PLoS Genetics 6(2), e1000862.

832 Hollander, J., Galindo, J., and Butlin, R. K. (2015). Selection on outlier loci and their

833 association with adaptive phenotypes in Littorina saxatilis contact zones. Journal of

834 Evolutionary Biology 28(2), 328-337.

835 Jakobsson, M., and Rosenberg, N. A. (2007). CLUMPP: a cluster matching and

836 permutation program for dealing with label switching and multimodality in analysis

837 of population structure. Bioinformatics 23(14), 1801-1806.

838 Jellinek, S., Harrison, P. A., Tuck, J., and Te, T. (2020). Replanting agricultural

839 landscapes: how well do plants survive after habitat restoration? Restoration Ecology

$840 \quad 28(6), 1454-1463$.

841 Jenkins, N., and Hoffman, A. A. (1999). Limits to the Southern Border of Drosophila

842 serrata: Cold Resistance, Heritable Variation, and Trade-Offs. Evolution 53(6), 1823-

8431834. 
844 Jessop, P. (1995) Response of arid vegetation to cattle grazing and the development of

845 indicators for range assessment with particular reference to the rangelands of northern

846 South Australia. MASc Thesis, Adelaide University, Adelaide

847 Jombart, T. (2008). adegenet: a R package for the multivariate analysis of genetic

848 markers. Bioinformatics 24(11), 1403-1405.

849 Jombart, T., Devillard, S., and Balloux, F. (2010). Discriminant analysis of principal

850 components: a new method for the analysis of genetically structured populations.

$851 \quad$ BMC Genetics 11, 94.

852 Kierepka, E. M., and Latch, E. K. (2015). Performance of partial statistics in

853 individual-based landscape genetics. Mol Ecol Resour 15(3), 512-525.

854 Kingsford, R. T. (2000). Ecological impacts of dams, water diversions and river

855 management on floodplains wetlands in Australia. Austral Ecology 25, 109-127.

856 Kirkpatrick, M., and Barton, N. H. (1997). Evolution of species' range. The American

857 Naturalist 150(1), 1-23.

858 Koizumi, I., Yamamoto, S., and Maekawa, K. (2006). Decomposed pairwise

859 regression analysis of genetic and geographic distances reveals a metapopulation

860 structure of stream-dwelling Dolly Varden charr. Mol Ecol 15(11), 3175-3189.

861 Lenormand, T. (2002). Gene flow and the limits to natural selection. Trends in

862 Ecology and Evolution 17(4), 183-189.

863 Lindenmayer, D. B., and Burgman, M. (2005). 'Practical Conservation Biology.'

864 (CSIRO Publishing: Melbourne.)

865 Lioubimtseva, E. (2004). Climate change in arid environments: revisiting the past to

866 understand the future. Progress in Physical Geography 28(4), 502-530.

867 Lischer, H. E., and Excoffier, L. (2012). PGDSpider: an automated data conversion

868 tool for connecting population genetics and genomics programs. Bioinformatics 28(2), $869 \quad 298-299$.

870 Lu, F., Lipka, A. E., Glaubitz, J., Elshire, R., Cherney, J. H., Casler, M. D., Buckler,

871 E. S., and Costich, D. E. (2013). Switchgrass genomic diversity, ploidy, and

872 evolution: novel insights from a network-based SNP discovery protocol. PLoS

873 Genetics 9(1), e1003215.

874 Mallen-Cooper, M., and Zampatti, B. P. (2020). Restoring the ecological integrity of a

875 dryland river: Why low flows in the Barwon-Darling River must flow. Ecological

876 Management \& Restoration 21(3), 218-228. 
877 Meirmans, P. G. (2012). The trouble with isolation by distance. Molecular Ecology

$878 \quad 21,2839-2846$.

879 Meirmans, P. G. (2020). genodive version 3.0: Easy-to-use software for the analysis

880 of genetic data of diploids and polyploids. Molecular Ecology Resources 20(4), 1126-

8811131.

882 Meirmans, P. G., and Van Tienderen, P. H. (2004). genotype and genodive: two

883 programs for the analysis of genetic diversity of asexual organisms. Molecular

884 Ecology Notes 4(4), 792-794.

885 Moerman, F., Fronhofer, E. A., Wagner, A., and Altermatt, F. (2020). Gene

886 swamping alters evolution during range expansions in the protist Tetrahymena

887 thermophila. Biol Lett 16(6), 20200244.

888 Morales, H. E., Pavlova, A., Amos, N., Major, R., Kilian, A., Greening, C., and

889 Sunnucks, P. (2018). Concordant divergence of mitogenomes and a mitonuclear gene

890 cluster in bird lineages inhabiting different climates. Nat Ecol Evol2018/07/11

891 10.1038/s41559-018-0606-3.

892 Morales, H. E., Pavlova, A., Joseph, L., and Sunnucks, P. (2015). Positive and

893 purifying selection in mitochondrial genomes of a bird with mitonuclear discordance.

894 Molecular Ecology 24(11), 2820-2837.

895 Moritz, C. (1994). Defining Evolutionary Significant Units for conservation. Trends

896 in Ecology and Evolution 9, 373-375.

897 Mynhardt, S., Bennett, N. C., and Bloomer, P. (2020). New insights from RADseq

898 data on differentiation in the Hottentot golden mole species complex from South

899 Africa. Mol Phylogenet Evol 143, 106667.

900 Navarro, T., Alados, C. L., and Cabezudo, B. (2006). Changes in plant functional

901 types in response to goat and sheep grazing in two semi-arid shrublands of SE Spain.

902 Journal of Arid Environments 64(2), 298-322.

903 Nei, M. (1977). F-statistics and analysis of gene diversity in subdivided populations.

904 Annals of Human Genetics 41(2), 225-233.

905 Network, M. C. S. (2012). What do we need to know about speciation? Trends in

906 Ecology and Evolution 27(1), 27-39.

907 Newbold, T., Hudson, L. N., Hill, S. L., Contu, S., Lysenko, I., Senior, R. A., Borger,

908 L., Bennett, D. J., Choimes, A., Collen, B., Day, J., De Palma, A., Diaz, S.,

909 Echeverria-Londono, S., Edgar, M. J., Feldman, A., Garon, M., Harrison, M. L.,

910 Alhusseini, T., Ingram, D. J., Itescu, Y., Kattge, J., Kemp, V., Kirkpatrick, L., Kleyer, 
911 M., Correia, D. L., Martin, C. D., Meiri, S., Novosolov, M., Pan, Y., Phillips, H. R.,

912 Purves, D. W., Robinson, A., Simpson, J., Tuck, S. L., Weiher, E., White, H. J.,

913 Ewers, R. M., Mace, G. M., Scharlemann, J. P., and Purvis, A. (2015). Global effects

914 of land use on local terrestrial biodiversity. Nature 520(7545), 45-50.

915 Norman, J. A., and Christidis, L. (2016). Ecological opportunity and the evolution of

916 habitat preferences in an arid-zone bird: implications for speciation in a climate-

917 modified landscape. Scientific Reports 6, 19613.

918 Nowicki, S., and Searcy, W. A. (2005). Song and Mate Choice in Birds: How the

919 Development of Behavior Helps Us Understand Function. The Auk 122(1), 1.

920 Oswald, J. A., Overcast, I., Mauck III, W. M., Andersen, M. J., and Smith, B. T.

921 (2017). Isolation with asymmetric gene flow during the nonsynchronous divergence

922 of dry forest birds. Molecular Ecology 26, 1386-1400.

923 Paparella, S., Araujo, S. S., Rossi, G., Wijayasinghe, M., Carbonera, D., and

924 Balestrazzi, A. (2015). Seed priming: state of the art and new perspectives. Plant Cell

925 Rep 34(8), 1281-1293.

926 Paradis, E. (2010). pegas: an R package for population genetics with an integrated-

927 modular approach. Bioinformatics 26(3), 419-420.

928 Peakall, R., and Smouse, P. E. (2012). GenAlEx 6.5: genetic analysis in Excel.

929 Population genetic software for teaching and research--an update. Bioinformatics

$930 \quad \mathbf{2 8}(19), 2537-2539$.

931 Peakall, R. O. D., and Smouse, P. E. (2006). GenAlEx 6: genetic analysis in Excel.

932 Population genetic software for teaching and research. Molecular Ecology Notes 6(1),

933 288-295.

934 Perez, M. F., Franco, F. F., Bombonato, J. R., Bonatelli, I. A. S., Khan, G., Romeiro-

935 Brito, M., Fegies, A. C., Ribeiro, P. M., Silva, G. A. R., Moraes, E. M., and Burridge,

936 C. (2018). Assessing population structure in the face of isolation by distance: Are we

937 neglecting the problem? Diversity and Distributions 24(12), 1883-1889.

938 Pickup, G. (1998). Desertification and climate change - the Australian perspective.

939 Climate Research 11, 51-63.

940 Poland, J. A., Brown, P. J., Sorrells, M. E., and Jannink, J.-L. (2012). Development of

941 high-density genetic maps for Barley and Wheat using a novel two-enzyme

942 genotyping-by-sequencing approach. PLoS ONE 7(2), e32253.

943 Pritchard, J. K., Stephens, M., and Donnelly, P. (2000). Inference of population

944 structure using multilocus genotype data. Genetics 155(2), 945-959. 
945 Purcell, S., Neale, B., Todd-Brown, K., Thomas, L., Ferreira, M. A., Bender, D.,

946 Maller, J., Sklar, P., de Bakker, P. I., Daly, M. J., and Sham, P. C. (2007). PLINK: a

947 tool set for whole-genome association and population-based linkage analyses. The

948 American Journal of Human Genetics 81(3), 559-575.

949 Rambaut, A., Drummond, A. J., Xie, D., Baele, G., and Suchard, M. A. (2015) Tracer

950 v1.6. http://beast.community

951 Reynolds, R. G. (2011) Islands Metapopulations and Archipelagos: Genetic

952 Equilibrium and Non-Equilibrium Dynamics of Structured Populations in teh Context 953 of Conservation., University of Tennessee,

954 Rosauer, D. F., Byrne, M., Blom, M. P. K., Coates, D. J., Donnellan, S., Doughty, P., 955 Keogh, J. S., Kinloch, J., Laver, R. J., Myers, C., Oliver, P. M., Potter, S., Rabosky,

956 D. L., Afonso Silva, A. C., Smith, J., and Moritz, C. (2018). Real-world conservation

957 planning for evolutionary diversity in the Kimberley, Australia, sidesteps uncertain

958 taxonomy. Conservation Letters 10.1111/conl.12438.

959 Rosenberg, N. A. (2004). DISTRUCT: a program for the graphical display of

960 population structure. Molecular Ecology Notes 4(1), 137-138.

961 Rossetto, M., Yap, J.-Y. S., Lemmon, J., Bain, D., Bragg, J., Hogbin, P., Gallagher,

962 R., Rutherford, S., Summerell, B., and Wilson, T. C. (2021). A conservation genomics

963 workflow to guide practical management actions. Global Ecology and Conservation

964 26, e01492.

965 Rousset, F. (1997). Genetic differentiation and estimation of gene flow from $F$ -

966 Statistics under isolation by distance. Genetics 145, 1219-1228.

967 Rousset, F. (2000). Genetic differentiation between individuals. Journal of

968 Evolutionary Biology 13, 58-62.

969 Saccheri, I., Kuussaari, M., Kankare, M., Vikman, P., Fortelius, W., and Hanski, I.

970 (1998). Inbreeding and extinction in a butterfly metapopulation. Nature 392, 491-494.

971 Sanchez-Guillen, R. A., Cordoba-Aguilar, A., Hansson, B., Ott, J., and Wellenreuther,

972 M. (2016). Evolutionary consequences of climate-induced range shifts in insects. Biol

973 Rev Camb Philos Soc 91(4), 1050-1064.

974 Seehausen, O., Butlin, R. K., Keller, I., Wagner, C. E., Boughman, J. W., Hohenlohe,

975 P. A., Peichel, C. L., Saetre, G.-P., Bank, C., Brännström, A., Brelsford, A., Clarkson,

976 C. S., Eroukhmanoff, F., Feder, J. L., Fischer, M. C., Foote, A. D., Franchini, P.,

977 Jiggins, C. D., Jones, F. C., Lindholm, A. K., Lucek, K., Maan, M. E., Marques, D.

978 A., Martin, S. H., Matthews, B., Meier, J. I., Möst, M., Nachman, M. W., Nonaka, E., 
979 Rennison, D. J., Schwarzer, J., Watson, E. T., Westram, A. M., and Widmer, A.

980 (2014). Genomics and the origin of species. Nature Reviews. Genetics 15(3), 176-192.

981 Skroblin, A., and Murphy, S. (2013). The conservation status of Australian malurids

982 and their value as models in understanding land-management issues. Emu - Austral

983 Ornithology 113(3), 309-318.

984 Slatyer, R. O. (1961). Methodology of a water balance study conducted on a desert

985 woodland (Acacia anuera F.Muell) community in central Australia. UNESCO Arid

986 Zone Research 16, 15-26.

987 Slender, A. L., Louter, M., Gardner, M. G., and Kleindorfer, S. (2017). Patterns of

988 morphological and mitochondrial diversity in parapatric subspecies of the Thick-

989 billed Grasswren (Amytornis modestus). Emu - Austral Ornithology 117(3), 264-275.

990 Slender, A. L., Louter, M., Gardner, M. G., and Kleindorfer, S. (2018a). Plant

991 community predicts the distribution and occurrence of thick-billed grasswren

992 subspecies (Amytornis modestus) in a region of parapatry. Australian Journal of

993 Zoology 65(4), 273-282.

994 Slender, A. L., Louter, M., Gardner, M. G., and Kleindorfer, S. (2018b). Thick-billed

995 grasswren (Amytornis modestus) songs differ across subspecies and elicit different

996 subspecific behavioural responses. Transactions of the Royal Society of South

997 Australia 142(2), 105-121.

998 Smith, L. M., and Burgoyne, L. A. (2004). Collecting, archiving and processing DNA

999 from wildlife samples using FTA® databasing paper. BMC Ecology 4, 4.

1000 Smith, T. B., Calsbeek, R., Wayne, R. K., Holder, K. H., Pires, D., and Bardeleben, C.

1001 (2005). Testing alternative mechanisms of evolutionary divergence in an African rain

1002 forest passerine bird. Journal of Evolutionary Biology 18(2), 257-268.

1003 Smouse, P. E., and Peakall, R. (1999). Spatial autocorrelation analysis of individual

1004 multiallele and multilocus genetic structure. Heredity 82, 561-573.

1005 Sousa, V., and Hey, J. (2013). Understanding the origin of species with genome-scale 1006 data: modelling gene flow. Nat Rev Genet 14(6), 404-414.

1007 Steiner, C. C., Putnam, A. S., Hoeck, P. E. A., and Ryder, O. A. (2013). Conservation

1008 genomics of threatened animal species. Annual Review of Animal Biosciences 1(1), 1009 261-281.

1010 Thompson, T. Q., Bellinger, M. R., O'Rourke, S. M., Prince, D. J., Stevenson, A. E.,

1011 Rodrigues, A. T., Sloat, M. R., Speller, C. F., Yang, D. Y., Butler, V. L., Banks, M.

1012 A., and Miller, M. R. (2019). Anthropogenic habitat alteration leads to rapid loss of 
1013 adaptive variation and restoration potential in wild salmon populations. Proc Natl

1014 Acad Sci U S A 116(1), 177-186.

1015 Toews, D. P. L., and Brelsford, A. (2012). The biogeography of mitochondrial and

1016 nuclear discordance in animals. Molecular Ecology 21(16), 3907-3930.

1017 Toews, D. P. L., Campagna, L., Taylor, S. A., Balakrishnan, C. N., Baldassarre, D. T.,

1018 Deane-Coe, P. E., Harvey, M. G., Hooper, D. M., Irwin, D. E., Judy, C. D., Mason, N.

1019 A., McCormack, J. E., McCracken, K. G., Oliveros, C. H., Safran, R. J., Scordato, E.

1020 S. C., Stryjewski, K. F., Tigano, A., Uy, J. A. C., and Winger, B. M. (2016). Genomic

1021 approaches to understanding population divergence and speciation in birds. The Auk

1022 133(1), 13-30.

1023 Vaghefi, S. A., Keykhai, M., Jahanbakhshi, F., Sheikholeslami, J., Ahmadi, A., Yang,

1024 H., and Abbaspour, K. C. (2019). The future of extreme climate in Iran. Sci Rep 9(1),

10251464.

1026 van Strien, M. J., Holderegger, R., and Van Heck, H. J. (2015). Isolation-by-distance

1027 in landscapes: considerations for landscape genetics. Heredity 114(1), 27-37.

1028 Wang, J. (2011). COANCESTRY: a program for simulating, estimating and analysing

1029 relatedness and inbreeding coefficients. Molecular Ecology Resources 11(1), 141-

1030145.

1031 Warren, W. C., Clayton, D. F., Ellegren, H., Arnold, A. P., Hillier, L. W., Kunstner,

1032 A., Searle, S., White, S., Vilella, A. J., Fairley, S., Heger, A., Kong, L., Ponting, C. P.,

1033 Jarvis, E. D., Mello, C. V., Minx, P., Lovell, P., Velho, T. A., Ferris, M.,

1034 Balakrishnan, C. N., Sinha, S., Blatti, C., London, S. E., Li, Y., Lin, Y. C., George, J.,

1035 Sweedler, J., Southey, B., Gunaratne, P., Watson, M., Nam, K., Backstrom, N.,

1036 Smeds, L., Nabholz, B., Itoh, Y., Whitney, O., Pfenning, A. R., Howard, J., Volker,

1037 M., Skinner, B. M., Griffin, D. K., Ye, L., McLaren, W. M., Flicek, P., Quesada, V.,

1038 Velasco, G., Lopez-Otin, C., Puente, X. S., Olender, T., Lancet, D., Smit, A. F.,

1039 Hubley, R., Konkel, M. K., Walker, J. A., Batzer, M. A., Gu, W., Pollock, D. D.,

1040 Chen, L., Cheng, Z., Eichler, E. E., Stapley, J., Slate, J., Ekblom, R., Birkhead, T.,

1041 Burke, T., Burt, D., Scharff, C., Adam, I., Richard, H., Sultan, M., Soldatov, A.,

1042 Lehrach, H., Edwards, S. V., Yang, S. P., Li, X., Graves, T., Fulton, L., Nelson, J.,

1043 Chinwalla, A., Hou, S., Mardis, E. R., and Wilson, R. K. (2010). The genome of a

1044 songbird. Nature 464(7289), 757-762.

1045 Wellborn, G. A., and Langerhans, R. B. (2015). Ecological opportunity and the

1046 adaptive diversification of lineages. Ecology and Evolution 5(1), 176-195. 
1047 Whiteley, A. R., Fitzpatrick, S. W., Funk, W. C., and Tallmon, D. A. (2015). Genetic

1048 rescue to the rescue. Trends Ecol Evol 30(1), 42-49.

1049 Whitlock, M. C., and Lotterhos, K. E. (2015). Reliable Detection of Loci Responsible

1050 for Local Adaptation: Inference of a Null Model through Trimming the Distribution

1051 of F(ST). Am Nat 186 Suppl 1, S24-36.

1052 Williams, O. B. (1982) The vegetation of arid Australia: a biotic appraisal. In

1053 'Evolution of the flora and fauna of arid Australia.' (Eds. WR Barker and PJM

1054 Greenslade) pp. 3-14. (Peacock Press: Adelaide)

1055 Willoughby, J. R., Sundaram, M., Wijayawardena, B. K., Kimble, S. J. A., Ji, Y.,

1056 Fernandez, N. B., Antonides, J. D., Lamb, M. C., Marra, N. J., and DeWoody, J. A.

1057 (2015). The reduction of genetic diversity in threatened vertebrates and new

1058 recommendations regarding IUCN conservation rankings. Biological Conservation

1059 191, 495-503.

1060 Wilson, G. A., and Rannala, B. (2003). Bayesian inference of recent migration rates

1061 using multilocus genotypes. Genetics 163, 1177-1191.

1062 Woinarski, J. C., Burbidge, A. A., and Harrison, P. L. (2015). Ongoing unraveling of

1063 a continental fauna: decline and extinction of Australian mammals since European

1064 settlement. Proceedings of the National Academy of Sciences 112(15), 4531-4540.

1065 Wood, Z. T., Wiegardt, A. K., Barton, K. L., Clark, J. D., Homola, J. J., Olsen, B. J.,

1066 King, B. L., Kovach, A. I., and Kinnison, M. T. (2021). Meta $\square$ analysis: Congruence

1067 of genomic and phenotypic differentiation across diverse natural study systems.

1068 Evolutionary Applications 10.1111/eva.13264.

1069 Zink, R. M. (2004). The role of subspecies in obscuring avian biological diversity and

1070 misleading conservation policy. Proceedings of the Royal Society of London. Series

1071 B: Biological Sciences 271(1539), 561-564. 
Figure 1. South Australian collection localities for samples of two thick-billed grasswren (TBGW) subspecies used for nuclear genomic sequencing. Localities are grouped into three zones. Sand dunes (grey shade) that run between Lake Eyre and Lake Torrens demarcate a novel habitat type where TBGWs are rarely observed; localities in zone A (solid circle) occur to the west of the sand dunes, localities in zone $\mathrm{AB}$ (grey square) occur immediately east of the sand dunes in a region of parapatry (referred to as the contact zone), and localities in zone B occur to the east of zone AB. Locality abbreviations are listed in Table S1. Numbers indicate sample size at that locality.

Figure 2. The pairwise genetic $\left(F_{\mathrm{ST}} /\left(1-F_{\mathrm{ST}}\right)\right)$ and geographic $(\log (1+\mathrm{km}))$ relationship between localities by zone (zone A: $n=6$, zone B: $n=3$, and zone AB: $n=2$ ) using a Mantel test $\left(\mathrm{R}^{2}=0.317\right)$. There was only one sample collected at the locality MTB, therefore this locality was excluded. The solid line is the line of best fit and the broken lines are the $95 \%$ confidence intervals.

Figure 3. Correlogram showing the spatial autocorrelation coefficient $r$ as a function of distance $(\mathrm{km})$ indicated by distance class (end point). Dotted lines are the $95 \% \mathrm{CI}$ about the null hypothesis of a random distribution of genotypes and error bars are 95\% CI of $r$.

Figure 4. PCA of 7543 loci where individuals from different zones are indicated with different shapes; zone $\mathrm{AB}$ (region of parapatry) are white triangles, zone $\mathrm{A}$ (A. $m$. indulkanna) are black diamonds, and zone B (A. m. raglessi) are grey circles.

Figure 5. Population assignment tests using 7543 n-SNP loci where $K=2$ for (a) DAPC and (b) STRUCTURE or using (c) mitochondrial haplotype for ND2 across three zones (Figure 1). Individuals are ordered by latitude in the order listed in Table S1. The proportion of each colour shows the posterior mean proportion of ancestry from the subspecies A. m. indulkanna or western haplotype (dark grey) and A. m. raglessi or eastern haplotype (light grey). Individuals marked with an asterisk were identified as admixed.

Figure 6. The proportion of migrants (average and standard deviation) assessed between each zone (zone A, zone B, and zone AB) with BAYESASS. Migration from zone A is in black, migration from zone $\mathrm{B}$ is in light gray, and migration from zone $\mathrm{AB}$ is in dark gray. The analysis was performed following a PCA to identify 200 loci with the highest loading that were used in the BAYESASS analysis. 
Table 1. Partitioning of the molecular variance among (1) individuals within zone A and zone B and (2) between zone A and zone B using AMOVA. Zone AB was merged with zone A or zone B in two separate analyses, excluded in a third, or analysed as a separate population. Variance was compared for both n-SNP and o-SNP datasets. Significant $p$-values $(<0.05)$ are shown in bold.

\begin{tabular}{|c|c|c|c|c|c|c|c|c|}
\hline $\begin{array}{l}\text { Zones } \\
\text { included }\end{array}$ & Dataset & Source of variation & Nested in & $\%$ variance & $\mathrm{SS}$ & F-stat & F-value & $P$-value \\
\hline \multirow[t]{2}{*}{$A+A B \vee B$} & n-SNP & Among individuals & Population & 0.081 & 145109.166 & Fis & 0.082 & $<0.001$ \\
\hline & & Among populations & -- & 0.007 & 2197.339 & Fst & 0.007 & $<0.001$ \\
\hline \multirow[t]{3}{*}{$A+A B \vee B$} & $n+o-$ & Among individuals & Population & 0.105 & 806.051 & Fis & 0.124 & $<0.001$ \\
\hline & SNP & & & & & & & \\
\hline & & Among populations & -- & 0.150 & 135.610 & Fst & 0.150 & $<0.001$ \\
\hline \multirow[t]{2}{*}{$\mathrm{B}+\mathrm{AB} \vee \mathrm{A}$} & n-SNP & Among individuals & Population & 0.082 & 145111.592 & Fis & 0.082 & $<0.001$ \\
\hline & & Among populations & -- & 0.007 & 2194.607 & Fst & 0.007 & $<0.001$ \\
\hline \multirow[t]{3}{*}{$\mathrm{B}+\mathrm{AB} \vee \mathrm{A}$} & $n+o-$ & Among individuals & Population & 0.094 & 788.943 & Fis & 0.115 & $<0.001$ \\
\hline & SNP & & & & & & & \\
\hline & & Among populations & -- & 0.185 & 159.104 & Fst & 0.185 & $<0.001$ \\
\hline \multirow[t]{5}{*}{$A \vee B$} & n-SNP & Among individuals & Population & 0.078 & 128405.213 & Fis & 0.079 & $<0.001$ \\
\hline & & Among populations & -- & 0.011 & 2591.425 & Fst & 0.011 & $<0.001$ \\
\hline & $n+o-$ & Among individuals & Population & 0.075 & 668.666 & Fis & 0.097 & $<0.001$ \\
\hline & SNP & & & & & & & \\
\hline & & Among populations & -- & 0.227 & 184.020 & Fst & 0.227 & $<0.001$ \\
\hline$A v B \vee A B$ & n-SNP & Among individuals & Population & 0.080 & 143301.521 & Fis & 0.081 & $<0.001$ \\
\hline
\end{tabular}




\begin{tabular}{|c|c|c|c|c|c|c|c|c|}
\hline & & Among populations & -- & 0.011 & 4209.131 & Fst & 0.011 & $<0.001$ \\
\hline \multirow[t]{3}{*}{$A \vee B \vee A B$} & $\mathrm{n}+\mathrm{o}-$ & Among individuals & Population & 0.087 & 136065.534 & Fis & 0.088 & $<0.001$ \\
\hline & SNP & & & & & & & \\
\hline & & Among populations & -- & 0.010 & 4008.841 & Fst & 0.010 & $<0.001$ \\
\hline
\end{tabular}


Table 2. Pairwise differentiation when zone $A B$ is merged with zone $A$, zone $A B$ is merged with zone $B$ or zone $A B$ is excluded for both the $n-$ SNP and n+o-SNP datasets. Cells show $F_{\mathrm{ST}}$ and $p$-values in parentheses. $P$-values were calculated after 10,000 permutations. Significant $p$ values $(<0.05)$ are shown in bold.

\begin{tabular}{|c|c|c|c|c|}
\hline Zone & $n-S N P$ & n-SNP & $n+o-S N P$ & $n+o-S N P$ \\
\hline & $\mathrm{A}$ & B & A & B \\
\hline $\mathrm{B}+\mathrm{AB}$ & $0.008(<\mathbf{0 . 0 0 1})$ & -- & $0.202(<\mathbf{0 . 0 0 1})$ & -- \\
\hline$A+A B$ & -- & $0.008(<\mathbf{0 . 0 0 1})$ & -- & $0.165(<\mathbf{0 . 0 0 1})$ \\
\hline $\mathrm{A}$ & -- & $0.010(<\mathbf{0 . 0 0 1})$ & -- & $0.227(<\mathbf{0 . 0 0 1})$ \\
\hline
\end{tabular}


Table 3. Fit of alternative isolation by distance models with and without putative outlier populations (see Figure 1 for population codes) $n$ shows the number of populations in the model, $\mathrm{AIC}_{\mathrm{C}}$ shows the corrected Akaike's information criteria, $\Delta \mathrm{AIC}_{\mathrm{C}}$ shows the difference in $\mathrm{AIC}_{\mathrm{C}}$ between alternative models. These values are used to assess the most likely model. Models are ranked from highest to lowest.

\begin{tabular}{llllll}
\hline Population excluded & $n$ & $R^{2}$ & $P$ & AIC $_{\mathrm{C}}$ & $\Delta$ AIC $_{\mathrm{C}}$ \\
\hline MUL, COP, OOE, WIC, WIT, COS, STC, & 3 & 0.92 & 0.182 & -26.635 & 0 \\
PEK & & & & & \\
MUL, COP, OOE, WIC, WIT, COS, STC & 4 & 0.883 & 0.005 & -39.507 & -12.872 \\
MUL, COP, OOE, WIC, WIT, COS & 5 & 0.825 & $<0.001$ & -48.503 & -21.868 \\
MUL, COP, OOE, WIC, WIT & 6 & 0.821 & $<0.001$ & -59.135 & -32.500 \\
MUL, COP, OOE, WIC & 7 & 0.795 & $<0.001$ & -67.610 & -40.975 \\
MUL, COP OOE & 8 & 0.742 & $<0.001$ & -76.613 & -49.978 \\
MUL, COP & 9 & 0.575 & $<0.001$ & -82.782 & -56.148 \\
MUL & 10 & 0.434 & $<0.001$ & -89.224 & -62.589 \\
None & 11 & 0.317 & $<0.001$ & -94.404 & -67.770 \\
\hline
\end{tabular}




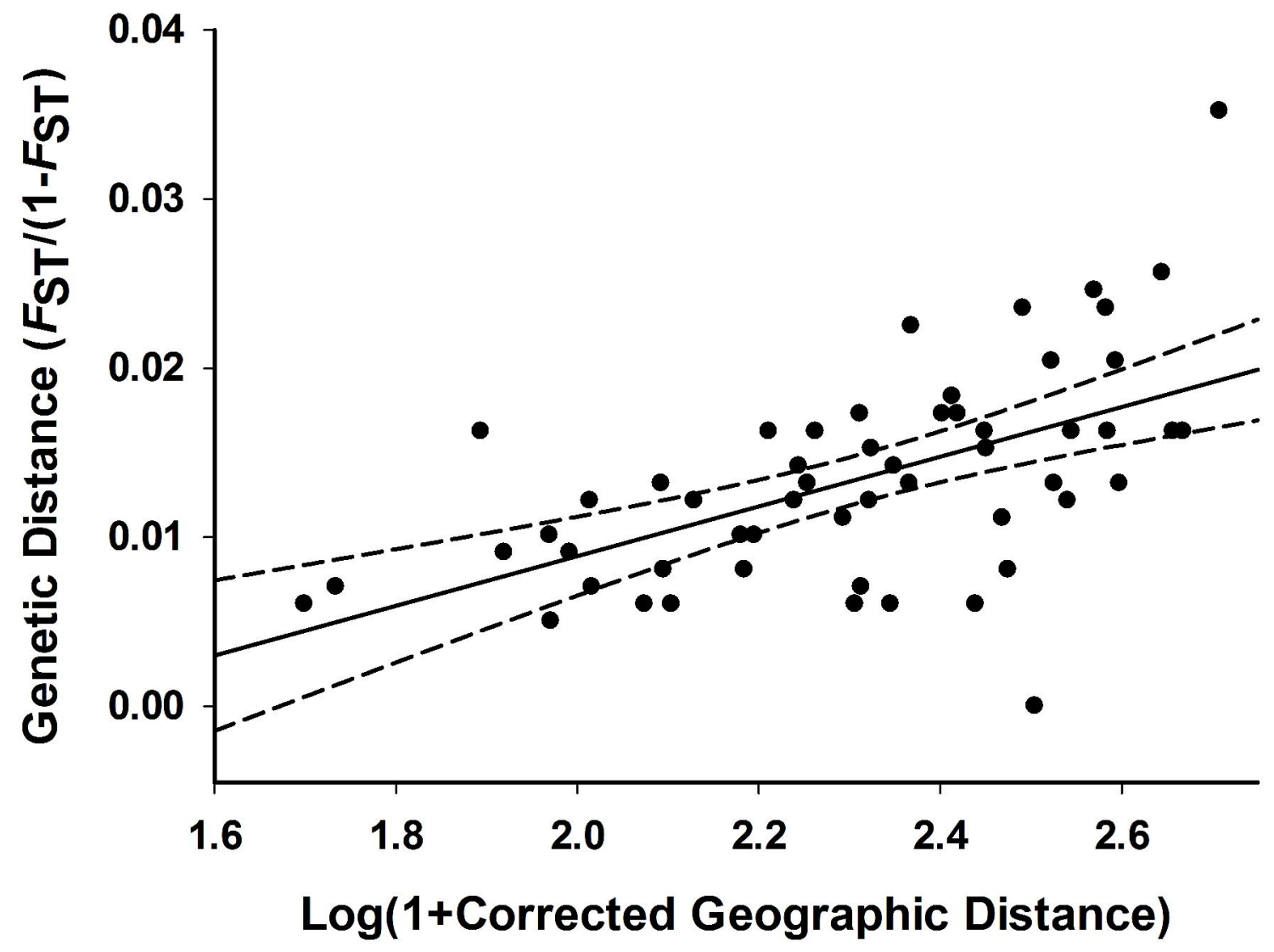




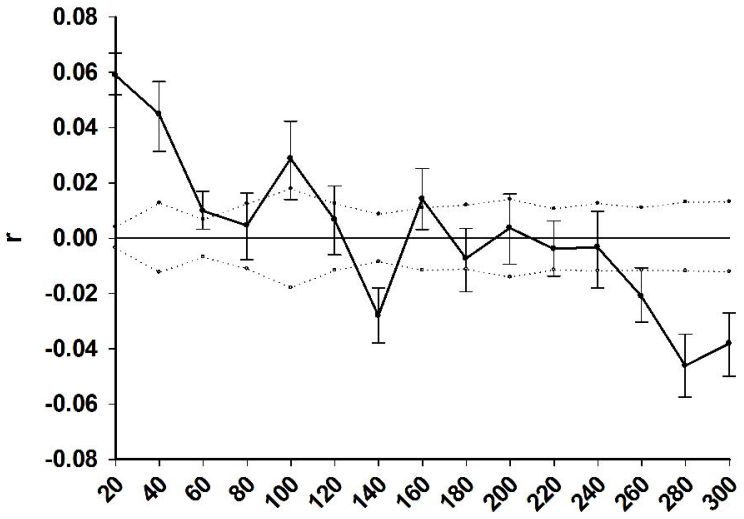

Distance Class 


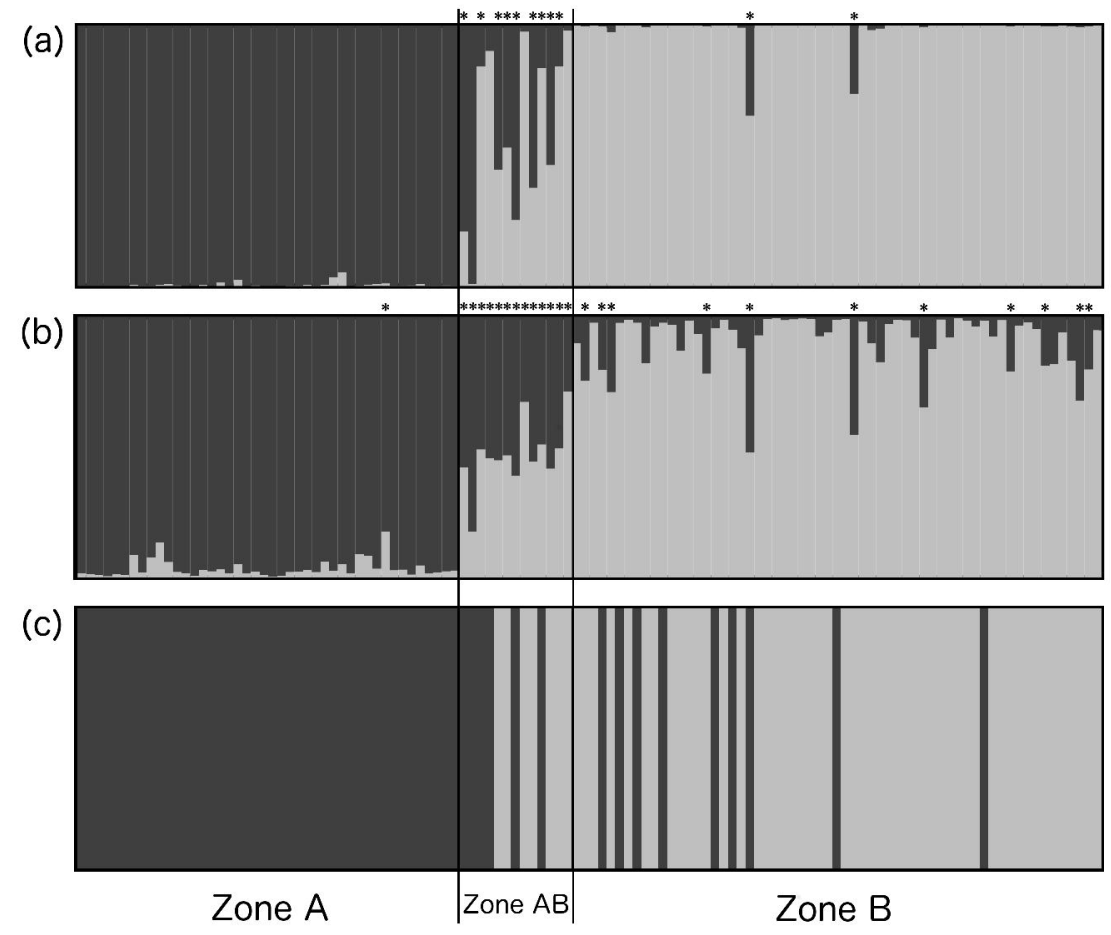




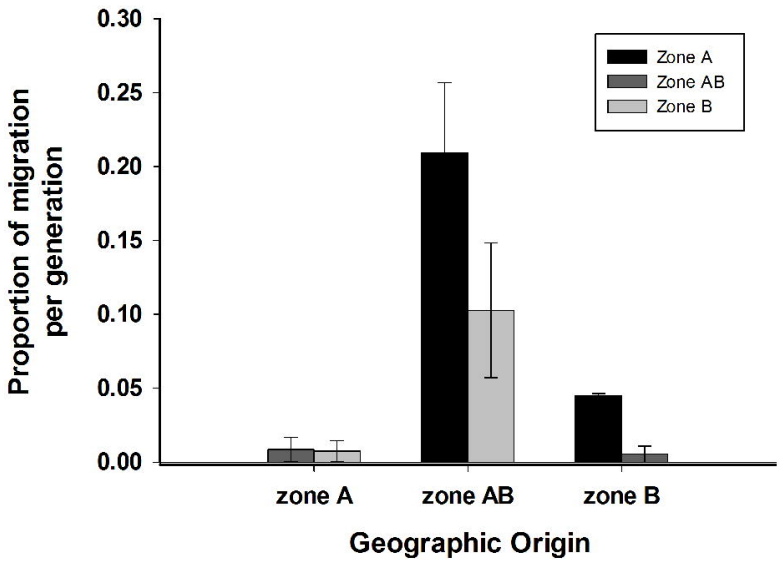

